\title{
El acogedor y guardador hacia una refundición de funciones del acogimiento temporal
}

\section{The cosy and guardian towards a refurbishment of functions of temporary fostercare}

\author{
Encarnación Abad Arenas ${ }^{1}$ \\ UNED \\ eabad@der.uned.es
}

Recepción: 17/12/18 Revisión: 18/12/18 Aceptación: 20/12/18 Publicación: 28/12/18

\section{Resumen:}

En el presente trabajo se analiza la repercusión que ha tenido el nuevo artículo 303. 1 CC modificado por Ley $26 / 2015$, de 28 de julio, haciéndose un especial hincapié en el refuerzo que ha supuesto para el régimen jurídico de la guarda de hecho, ya que se agiliza una medida en pro de la protección de menores de edad y personas con discapacidad. También, se alude a las carencias de respuesta que presenta esta reforma respecto de los requerimientos del sistema de apoyos de la Convención de Naciones Unidas de las personas con discapacidad, así como a las contradicciones que presenta. Asimismo, nos detenemos en la incidencia que han tenido las últimas modificaciones legislativas en la simplificación de la constitución del acogimiento familiar, en la concreción de las distintas modalidades de acogimiento vigentes en la actualidad. Para finalizar, se analizan, entre otros, los derechos y deberes del acogedor y de los menores acogidos y, se incide en los requisitos de idoneidad.

Palabras Clave: Sistema de apoyos, Guarda de hecho, Menores, Acogedor.

\begin{abstract}
:
In this paper analysed the impact that has had the new article 303. 1 CC amended by Law $26 / 2015$, de 28 de july, making a special emphasis in the reinforcement that it has meant for the legal regime of the guardian in fact, because it speeds up a measure in pro the protection of minors and people with disabilities. Also, reference is made to the short comings of response that presents this reform with respect to the requirements of the system of supports of the United Nations Convention of persons with disabilities, as well as
\end{abstract}

\footnotetext{
${ }^{1}$ Profesora Doctora UNED (Contratada Doctora Acreditada).
} 
the contradictions that presented. Also, we stop in the incidence who have had the latest legislative amendment sin the simplification the Constitution of the family Foster care, in the realization of the various forms of current foster care today. Finally, is analysed, among others, the rights and duties of the cozy and the minors and, it affects in the suitability requirements.

Keywords: support system, Guard off act, Minors, Cozy.

\section{Sumario:}

1. El encuadramiento en el nuevo sistema de apoyos en la discapacidad de la guarda de hecho y su equiparación al acogimiento

2. El acogimiento familiar. Antecedentes y vigencia normativa

3. Modalidades de acogimiento

4. Idoneidad para ser acogedores

5. Constitución del acogimiento familiar

6. El Estatuto del acogedor: derechos y deberes

7. Derechos de los menores acogidos

8. La remoción de la guarda y el cese del acogimiento

9. Conclusiones

10. Referencias bibliográficas

\section{EL ENCUADRAMIENTO EN EL NUEVO SISTEMA DE APOYOS EN LA DISCAPACIDAD DE LA GUARDA DE HECHO Y SU EQUIPARACIÓN AL ACOGIMIENTO}

En primer lugar, conviene precisar que con Ley 26/2015, de 28 de julio, de modificación del sistema de protección a la infancia y a la adolescencia, se introduce una modificación en la regulación de la guarda de hecho, dándose con ello una nueva dicción al artículo 303 CC, reformulándose con ello su incidencia entre las instituciones de protección de los menores de edad y las personas con discapacidad.

En este sentido, el contenido del mencionado precepto se divide en dos apartados diferentes, encontrándose el primero de ellos integrado por dos párrafos. De modo que, de la dicción contenida en el párrafo primero -que prácticamente es una reproducción literal del anterior-, se observa que presenta alguna mejora de carácter técnico, debido a que suprime la referencia al derogado artículo 203 CC y, adecua su terminología a los cánones de la Convención de Naciones Unidas sobre las personas con discapacidad, ya que sustituye la referencia al menor o presunto incapaz sujeto a la guarda de hecho, por la del «menor»o 
«persona que pudiera precisar de una institución de protección y apoyo»².

Con estas modificaciones se mantienen las facultades otorgadas por la redacción previa a la autoridad judicial, para el supuesto de que tenga conocimiento de la existencia de un guardador de hecho -es decir, que podrá requerirle información sobre la persona y bienes de quien esté sujeto a su cuidado y de su actuación en relación con éstos y, a la par, establecer las medidas de control y vigilancia que considere oportunas-. Lo anterior, como GARCÍA GARNICA -acertadamente- precisa «tendrá cabida sin perjuicio de que el Ministerio Fiscal pida y el Juez disponga, incluso de oficio, la constitución de la tutela [ex art. $228 \mathrm{CC}$ ]» ${ }^{3}$.

En este sentido, PARRA LUCÁN -con anterioridad a la reforma- afirmaba que "la intervención judicial propicia que ya no podamos hablar de guarda de hecho, pues en todo caso la persona a quien se encomiendan las funciones tutelares queda sometida a un control judicial y la situación ya no es propiamente de hecho, fáctica» ${ }^{4}$.

A mayor abundamiento, y con la pretensión de otorgar un mayor reconocimiento de la labor desempeñada por el guardador de hecho, el legislador ha introducido en el artículo 303. $1 \mathrm{CC}$, un segundo párrafo que prevé que: "Cautelarmente, mientras se mantenga la situación de guarda de hecho y hasta que se constituya la medida de protección adecuada, si procediera, se podrán otorgar judicialmente facultades tutelares a los guardadores. Igualmente, si fuera menor de edad, se podrá constituir un acogimiento temporal, siendo acogedores los guardadores». De forma tal que, en la actualidad, se contempla la posibilidad judicial de otorgar facultades tutelares al guardador que, aunque se incorpora, indudablemente, al Derecho civil común con carácter cautelar, lo cierto es que ni se matiza el alcance de dichas facultades, ni su incidencia sobre la patria potestad o la tutela que

\footnotetext{
${ }^{2}$ Recientemente, en concreto, el 29 de noviembre de 2018 el Pleno del Consejo General del Poder Judicial ha aprobado un informe que avala el Anteproyecto de Ley elaborado por el Ministerio de Justicia para reformar la legislación civil y procesal en materia de discapacidad. En este sentido, con esta reforma se suprime del precepto la referencia a la «persona que pudiera precisar de una institución de protección y apoyo». Referencia contenida por el vigente artículo 303. 1 CC y, que se encuentra suprimida en el artículo 263.1 del Anteproyecto, dándose con ello una priorización al autogobierno y la autonomía de la persona con discapacidad y, convirtiéndose con esta reforma la curatela en el sistema de guarda legal adecuado para los supuestos en que no exista una medida de apoyo adecuada o suficiente para la persona con discapacidad. No obstante, conviene precisar que el informe del anteproyecto tiene presente las consecuencias que pueden derivarse de desaparición del sistema de tutela de autoridad, debido a que ello podría generar situaciones que serían incompatibles con el derecho fundamental a la tutela judicial efectiva de las personas con discapacidad, al dejarse cuestiones que serían ajenas al efectivo control de los jueces.

${ }^{3}$ "La guarda como medida de protección de menores y personas con discapacidad tras su reforma por la Ley 26/2015, de 28 de julio, de modificación del sistema de protección a la infancia y a la adolescencia», Anuario de derecho civil, vol. 70, número 4, 2017, p. 1392.

${ }^{4}$ "La guarda de hecho de las personas con discapacidad». En Los mecanismos de guarda legal de las personas con discapacidad tras la Convención de Naciones Unidas, (coordinadora Sofía de Salas Murillo), 2013, p. 227. Y, vid, las aportaciones de LECIÑERA IBARRA, A. "La nueva dimensión de la guarda de hecho de las personas con discapacidad tras la reforma del art. 303 CC por la Ley 26/2015, de 28 de julio, de modificación del sistema de protección a la infancia y a la adolescencia», Revista de derecho de familia: Doctrina, Jurisprudencia, Legislación, número 73, 2016, p. 92.
} 
recaiga sobre el menor o la persona con discapacidad -posibilidad que ya se contemplaba en algunos derechos forales ${ }^{5}$.

A lo anterior, conviene matizar que, aunque se introduce la posibilidad de la constitución del acogimiento temporal a cargo del guardador, lo cierto es que ello ha originado ciertas dudas en caso de que la persona sujeta a la guarda de hecho sea menor de edad [art. 303. 1, párr. 2. CC]. Posibilidad con la que se modifica la naturaleza de la relación establecida entre el guardado y el guardador, y que a partir de la constitución del acogimiento le será de aplicabilidad la normativa que regula a este último.

A mayor abundamiento, conviene precisar que con la reforma practicada por Ley $26 / 2015$, de 28 de julio, para el supuesto de que la persona sujeta a la guarda de hecho sea mayor de edad con capacidad de obrar disminuida, aunque se le ha dado una cierta mejora tanto sistemática como terminológica, puesto que se reemplaza la antigua referencia a los incapaces por la de persona con la capacidad modificada [art. 239 bis CC] -expresión última más acorde a los dictados de la Convención de Naciones Unidas de 2006-, lo cierto es que sigue faltando una cierta congruencia interna del CC y del sistema de protección de menores y personas con discapacidad ${ }^{6}$.

Por otra parte, conviene precisar que la norma contempla otras imprecisiones, así, aunque no precisa a quién corresponde constituir este acogimiento, lo cierto es que de su tenor literal se puede afirmar que podrá ser constituido por la autoridad judicial, a través de un procedimiento de jurisdicción voluntaria ${ }^{7}$. Sin embargo, si el menor no se encontrase en situación de desamparo, se sobreentenderá que podrá delegarse el acogimiento -a través de resolución administrativa- al guardador de hecho ${ }^{8}$. Supuesto, en el que será necesario,

\footnotetext{
${ }^{5}$ Así, entre otros, el artículo 159. 1 del Decreto Legislativo 1/2011, de 22 de marzo, del Gobierno de Aragón, por el que se aprueba, con el título de "Código del Derecho Foral de Aragón», el Texto Refundido de las Leyes civiles aragonesas, prevé que: "La actuación del guardador de hecho en función tutelar debe limitarse a cuidar de la persona protegida y a realizar los actos de administración de sus bienes que sean necesarios. La realización de estos actos comporta, frente a terceros, la necesaria representación legal». También, el artículo 225-3 de la Ley 25/2010, de 29 de julio, del libro segundo del Código Civil de Cataluña, relativo a la persona y la familia, en su párrafo segundo establece que: "En la guarda de hecho de personas que estén en potestad parental o en tutela, la autoridad judicial puede conferir al guardador, si lo solicitan aquellas personas, las funciones tutelares, siempre y cuando concurran circunstancias que lo hagan aconsejable. Las funciones tutelares se atribuyen en un procedimiento de jurisdicción voluntaria, con la audiencia de las personas titulares de la potestad o tutela si es posible. Esta atribución comporta la suspensión de la potestad parental o tutela».

${ }^{6}$ Vid., en este sentido, y para una mayor argumentación las aportaciones de: GARCíA GARNICA, M. $\underline{a}$ C. «Discapacidad y dependencia (II): Configuración y contenido de su situación jurídica». En Tratado de derecho de la persona física, (coordinadora M. del Carmen Gete-Alonso Calera y Judith Solé Resina), vol. 2, 2013, pp. 236 y ss.

${ }^{7}$ En este sentido, vid., la Disposición Adicional Segunda de la Ley 15/2015, de 2 de julio, de Jurisdicción Voluntaria, por la que se establece el «Régimen jurídico aplicable al acogimiento de menores» y, más en concreto el apartado primero.

${ }^{8}$ En este sentido, se precisa en la Exposición de Motivos de la Ley 15/2015, de 2 de julio, de la Jurisdicción Voluntaria que el acogimiento de menores «se ha regulado por separado en previsión de una futura desjudicialización del procedimiento».
} 
comunicar dicha resolución tanto al Ministerio Fiscal y, al Juez que acordase la tutela ordinaria, como su notificación a los progenitores, al tutor y al acogido si éste es mayor de doce años. A lo anterior se añade que también deberán hacerse constar las causas y demás efectos derivados de dicha resolución, sin perjuicio de que la Entidad Pública pueda proceder de forma paralela a practicar las diligencias necesarias de averiguación y constatación de las circunstancias acaecidas [art. 172. 4 CC] ${ }^{9}$.

Tampoco, el artículo 303. 1 concreta la duración máxima que debe tener el acogimiento temporal, extremo que sí se encuentra determinado por el artículo 173 bis letra b) al precisar que «este acogimiento tendrá una duración máxima de dos años, salvo que el interés superior del menor aconseje la prórroga de la medida por la previsible e inmediata reintegración familiar, o la adopción de otra medida de protección definitiva».

En este sentido, GARCÍA GARNICA con acierto precisa que "aunque lo propio sería que el menor regresase con sus progenitores o tutores transcurrido dicho plazo o, su prórroga, lo cierto es que si no se dan las circunstancias adecuadas para ese regreso, pero el menor está siendo debidamente atendido, al amparo de lo dispuesto en la letra c) de este último precepto, procederá someter a revisión la situación de acogimiento temporal, constituyendo en su caso un acogimiento permanente, a iniciativa de la Entidad pública, el Ministerio Fiscal, el propio acogedor, el acogido mayor de doce años, o cualquier otra persona interesada; sin perjuicio de la adopción de otra medida de protección definitiva ${ }^{10}$.

En este punto, el artículo 173 bis letra c) CC, dispone que «la Entidad Pública podrá solicitar del Juez que atribuya a los acogedores permanentes aquellas facultades de la tutela que faciliten el desempeño de sus responsabilidades, atendiendo, en todo caso, al interés superior del menor». Y para el caso de que se éste se trate de persona física, nos encontraremos ante un acogimiento familiar que produce «la plena participación del menor o incapacitado en la vida de familia e impone a quien lo recibe las obligaciones de velar por él, tenerlo en su compañía y alimentarlo, así como educar y procurar una formación integral al menor y promover la adquisición o recuperación de la capacidad del incapacitado y su mejor inserción en la sociedad» [art. 173. 1 CC].

Para finalizar, se introduce un párrafo segundo en el artículo 303. 1 CC, en el que se establece que procederá la declaración de situación de desamparo de los menores y de las personas con la capacidad modificada judicialmente en situación de guarda de hecho, cuando, además de lo anterior, se den los presupuestos objetivos de falta de asistencia contemplados en el artículo 172 CC, con respecto a los menores, y en el artículo 239 bis CC, en relación con las personas con capacidad de obrar modificada ${ }^{11}$. Mientras que, por el contrario, si el menor está siendo debidamente atendido por un guardador de hecho,

\footnotetext{
${ }^{9}$ Así, GARCÍA GARNICA, «La guarda como medida..., op. cit., p. 1395.

${ }^{10}$ «La guarda como medida..., op. cit., p. 1396.

${ }^{11}$ En este sentido, LECIÑERA IBARRA, es partidario de que esta previsión resulta absolutamente criticable por ociosa, ya que si el guardador de hecho cumple adecuadamente su función es evidente que faltan los presupuestos para declarar en situación de desamparo al guardado (op. cit., p. 9).
} 
además de no proceder la declaración de su situación de desamparo, debido a la inexistencia de su presupuesto objetivo, a la par, la reforma ha legitimado de forma expresa al guardador de hecho para promover la privación o suspensión de la patria potestad, la remoción de la tutela o el nombramiento de tutor [art. 303. 2 párr. 2.ํ CC].

En síntesis, conviene precisar que la posibilidad de atribuir funciones tutelares o el acogimiento temporal al guardador de hecho origina la atribución de un mayor reconocimiento tanto a su funcionalidad como a la institución de protección de menores y de las personas con discapacidad, debido a que no se precisa para su constitución de un procedimiento judicial previo, al agilizarse los trámites y los costes que ello origina. $Y$, en consecuencia, nos encontramos ante una nueva institución de protección de menores y de personas con discapacidad -es decir, ante una guarda de derecho, más que, de hecho-, en aquellos supuestos en que la autoridad judicial reconozca su existencia, sometiéndola a medidas de control o, atribuyéndole funciones tutelares.

Por cuanto atañe a la legitimación judicial que ostenta esta figura, conviene precisar que ello ha suscitado ciertas dudas en doctrina ${ }^{12}$, debido a que esta legitimación únicamente queda circunscrita a la dotación de un título de legitimación y, a la par, de un medio de prueba de su condición de guardador, que todo apunta a que permite su anotación en el Registro Civil.

Lo anterior es debido a que aun a pesar de que con Ley 1/2009, de 25 de marzo, de reforma de la Ley de 8 de junio de 1957, sobre el Registro Civil, en materia de incapacitaciones, cargos tutelares y administradores de patrimonios protegidos, y de la Ley 41/2003, de 18 de noviembre, sobre protección patrimonial de las personas con discapacidad y de modificación del Código Civil, de la Ley de Enjuiciamiento Civil de la normativa tributaria con esta finalidad, se dotó de una nueva redacción al artículo 38. 6. de la Ley del Registro Civil de 1956, permitiéndose con ello la anotación registral -a petición del Ministerio Fiscal o de cualquier interesado- a efectos informativos de la existencia de un guardador de hecho y, en su caso, de las medidas judiciales de control y vigilancia adoptadas respecto del menor o presunto incapaz, lo cierto es que la norma no ha resuelto la cuestión de cómo podrá el guardador o cualquier otro interesado proceder a acreditar su existencia ante el Registro Civil a estos efectos. Cuestión que tampoco ha sido resuelta por la dicción contenida en el artículo 40. 9. relativo a "el acogimiento, la guarda administrativa y la guarda de hecho» de la Ley 20/2011, de 21 de julio, del Registro Civil.

Anotación registral que aunque, resulta innegable, que podría haber sido una de las medidas cautelares a las que se podría haber amparado judicialmente la guarda de hecho, lo cierto es que ha planteado una cuestión concretada en determinar cuál es el título que

\footnotetext{
${ }^{12}$ En relación a la legitimación activa y a las funciones generales del órgano tutelar de la guarda de hecho, vid., las argumentaciones de MORETÓN SANZ, M. ․ F. "El guardador de hecho ante la dependencia. Revisión de los procedimientos autonómicos y de las declaraciones "bajo su responsabilidad", Diario La Ley, número 7246, 2009, p. 2 y, también, GARCÍA GARNICA, M. C. «La guarda como medida..., op. cit., p. 1398.
} 
realmente puede permitir a cualquier interesado e, incluso, al propio guardador de hecho solicitar esa anotación en el Registro Civil, cuestionándose con ello la posibilidad de que él pudiese promoverla, debido a la dificultad que originaba la acreditación de una situación por definición puramente fáctica ${ }^{13}$, al plantearse la discrepancia de si dicha anotación puede o no suponer un título de legitimación para el guardador de hecho en el tráfico jurídico privado $^{14}$.

En suma, con la nueva redacción del párrafo segundo del artículo 303. 1 se solventa en parte esas dudas, debido al hecho de que la resolución judicial que atribuye funciones tutelares al guardador de hecho constituye un título de legitimación, que podrá hacerse valer por el propio guardador para instar la anotación de esta situación en el Registro Civil, pudiéndose con ello informar de su existencia a terceros. No obstante, ello no impide el hecho de que varias personas se arroguen de forma simultánea la condición de guardador de hecho de otra. Supuesto que se solventará en atención a lo que resulte más favorable para el interés de la persona sujeta a su guarda [ex artículo $304 \mathrm{CC}]^{15}$.

Sin embargo y, a diferencia de algunos derechos forales, esta reforma no contempla el deber de comunicar la existencia de la guarda de hecho al Juez, al Ministerio Fiscal o en su caso a la Entidad pública encargada de la protección de menores o de las personas con discapacidad en el territorio correspondiente ${ }^{16}$.

En síntesis, con esta reforma se refuerza el régimen jurídico de la guarda de hecho, agilizándose con ello una medida en pro de la protección de menores de edad y personas

\footnotetext{
${ }^{13}$ En este sentido, se ha pronunciado el Decreto Legislativo 1/2011, de 22 de marzo, del Gobierno de Aragón, por el que se aprueba, con el título de "Código del Derecho Foral de Aragón», el Texto Refundido de las Leyes civiles aragonesas, al prever en los párrafos 2 y 3 del artículo 159 que: «2. Para justificar la necesidad del acto y la condición de guardador de hecho será suficiente la declaración, en ese sentido, de la Junta de Parientes de la persona protegida. 3. El acto declarado necesario por la Junta de Parientes será válido; los demás serán anulables si no eran necesarios, salvo si han redundado en utilidad de la persona protegida».

${ }^{14}$ En doctrina, vid., en contra del tráfico jurídico privado PARRA LUCAN, M.a A. "Comentario al artículo 303». En Comentarios al Código Civil, T. II, (director Rodrigo Bercovitz Rodríguez-Cano), Ed. Tirant Lo Blanch, 2013, p. 2539.

${ }^{15}$ Téngase presente que, por analogía, este criterio está avalado por lo establecido en relación con los supuestos de concurrencia de más de un tutor (GARCÍA GARNICA, «La guarda como medida..., op. cit., Nt. 44, p. 1400).

${ }^{16}$ Así, el artículo 157 del Decreto Legislativo 1/2011, de 22 de marzo, del Gobierno de Aragón, por el que se aprueba, con el título de "Código del Derecho Foral de Aragón», el Texto Refundido de las Leyes civiles aragonesas, establece que «el guardador debe poner el hecho de la guarda en conocimiento del Juez o del Ministerio Fiscal». Por su parte, el artículo 225-2 de la Ley 25/2010, de 29 de julio, del libro segundo del Código Civil de Cataluña, relativo a la persona y la familia, establece que: «1. El guardador de hecho que ha acogido transitoriamente a un menor que ha sido desamparado por las personas que tienen la obligación de cuidarlo debe comunicarlo a la entidad pública competente en materia de protección de menores o a la autoridad judicial en el plazo de setenta y dos horas desde el inicio de la guarda. 2. En caso de guarda de hecho de una persona mayor de edad en quien se da una causa de incapacitación, si esta está en un establecimiento residencial, la persona titular del establecimiento residencial debe comunicarlo a la autoridad judicial o al ministerio fiscal en el plazo fijado por el apartado 1».
} 
con discapacidad ante aquellas situaciones derivadas, bien del indebido cumplimiento de sus funciones por parte de sus propios progenitores o tutores, o bien por la inexistencia de estas personas. De modo que, aunque se introducen ciertas previsiones, cuya finalidad se concretan en otorgar una estabilidad y una seguridad jurídica a los guardadores de hecho, lo cierto es que -a diferencia de algunos derechos forales ${ }^{17}$ que han plasmado, entre otros extremos, su conceptualización, comunicación y extinción- se ha perdido la oportunidad de realizar una reforma más completa de la institución de la guarda.

Por otra parte, al no realizarse una reforma integral del sistema de protección de los menores y de las personas con discapacidad -puesto que la reforma únicamente se ha centrado en el sistema de protección de la infancia y la adolescencia-, se observa la carencia de respuesta a buena parte de los requerimientos del sistema de apoyos de la Convención de Naciones Unidas de las personas con discapacidad, originándose con ello numerosas incongruencias y contradicciones, cuando lo propio habría sido realizar una reforma más completa y sistemática, con la pretensión de adaptar nuestro ordenamiento jurídico a las disposiciones contenidas en la Convención de Naciones Unidas de las personas con discapacidad.

En definitiva, lógico habría sido que, de una parte, la reforma legislativa hubiese contemplado -dentro del régimen jurídico de la guarda de hecho- un deber de comunicación a la autoridad judicial, al Ministerio Fiscal o, a la Entidad Pública competente en el respectivo territorio para la protección de los menores de edad o de las personas con discapacidad, de otra, se debería haber delimitado el supuesto de hecho de la guarda y de las facultades del guardador, con la finalidad de establecer a qué ámbito quedan circunscritos y, finalmente, resulta cuestionable que se haya advertido la posibilidad de que el guardador asuma únicamente funciones tutelares, sin contemplar como LECIÑERA IBARRA dice "una posible "guarda de apoyo» o asunción por el guardador de un papel análogo al del curador» ${ }^{18}$.

Esta previsión como acertadamente GARCÍA GARNICA precisa habría sido concordante con los dictados establecidos por la Convención de derechos de las personas con discapacidad, así como con la doctrina jurisprudencial que incentiva el recurso a la

\footnotetext{
${ }^{17}$ En este sentido, el artículo 156 del Decreto Legislativo 1/2011, de 22 de marzo, del Gobierno de Aragón, por el que se aprueba, con el título de "Código del Derecho Foral de Aragón», el Texto Refundido de las Leyes civiles aragonesas, establece que: "Guardador de hecho es la persona física o jurídica que, por iniciativa propia, se ocupa transitoriamente de la guarda de un menor o incapacitado en situación de desamparo o de una persona que podría ser incapacitada" y, el artículo 157 prevé que: "El guardador debe poner el hecho de la guarda en conocimiento del Juez o del Ministerio Fiscal». Por su parte, el artículo 225-2 de la Ley 25/2010, de 29 de julio, del libro segundo del Código Civil de Cataluña, relativo a la persona y la familia, establece que: «Es guardadora de hecho la persona física o jurídica que cuida de un menor o de una persona en quien se da una causa de incapacitación, si no está en potestad parental o tutela o, aunque lo esté, si los titulares de estas funciones no las ejercen", en cuanto a la comunicación de la guarda de hecho, Cfr., artículo 225-2 y, finalmente, su artículo 225-5 en su apartado primero, dispone que: «La guarda de hecho se extingue por desaparición de las causas que la motivaron, por la declaración de desamparo del menor, por el nombramiento de defensor judicial o por la constitución del pertinente régimen de protección".

${ }^{18}$ Op. cit., pp. 11 y 12.
} 
curatela como medida de protección de las personas con discapacidad psíquica, frente a la preexistente primacía de la tutela, procurando con ello realizar una interpretación y aplicación de nuestro ordenamiento jurídico acorde con los principios recogidos en la mencionada Convención, así como con el sistema de apoyos previsto en su artículo 12. Previsiones todas que deberían haber propiciado una profunda reforma de nuestro ordenamiento en materia de discapacidad, que indudablemente, no se ha realizado ${ }^{19}$.

\section{EL ACOGIMIENTO FAMILIAR. ANTECEDENTES Y VIGENCIA NORMATIVA}

En primer lugar, conviene precisar que el acogimiento familiar se concibe como una medida de protección del menor en interés de éste, siendo su pretensión última, la de procurar al menor que se encuentra separado de su familia, su atención ya en un contexto familiar o ya de convivencia adecuado, pudiendo ser éste con carácter provisional, temporal, permanente $\mathrm{o}$, incluso, como un paso previo a su ulterior adopción ${ }^{20}$.

Por otra parte, conviene destacar que pese a que en nuestro país el marco legal del acogimiento familiar como sistema formal de protección de la infancia comienzo a vislumbrarse a finales de los años 80, lo cierto es que sería a finales de 1996 cuando con la aprobación de la Ley Orgánica 1/1996, de 15 de enero, de Protección Jurídica del Menor, modificación del Código civil y de la Ley de Enjuiciamiento Civil, se instaurase un instrumento de reconocimiento y regulación de los aspectos legales del acogimiento familiar en todas sus formas.

Téngase presente que esta figura como práctica social informal ha existido durante siglos. De ahí que las distintas instancias e instituciones jurídicas, tanto internacionales como españolas hayan consolidado de forma progresiva una doctrina que abogue por la especial protección de la familia y la infancia ${ }^{21}$.

\footnotetext{
19 «La guarda como medida..., op. cit., p. 1403.

${ }^{20}$ En este sentido, ABAD ARENAS, E. precisa que el acogimiento de menores en nuestro país se encuentra enmarcado dentro de las medidas de protección a la infancia que se han venido desarrollando, tanto a nivel internacional como nacional, para los supuestos de detección de supuestos que comportan una problemática socio-familiar $y$, en los que se ha planteado la conveniencia de que el menor sea acogido por una familia de forma transitoria o permanente, debido a que su familia no puede o, no quiere hacerse cargo de las obligaciones derivadas de la paternidad («Acogimiento de Menores. Teoría y Práctica», (Coordinadora Inmaculada García Presas), 1. a ed., Ed., Juruá Editorial, Porto, Portugal, 2018, pp. 5 y ss.) También, ROSSER LIMIÑANA puntualiza -acertadamente- que la normativa sobre esta medida "encuentra su origen como consecuencia de los numerosos estudios que evidenciaron los efectos negativos que originaba la institucionalización de menores en su desarrollo personal y adaptación social» ("Marco legislativo del acogimiento familiar», Alternativas. Cuadernos de Trabajo Social, número 6, 1998, p. 259).

${ }^{21}$ A nivel Internacional y, en lo referente a la protección infantil, entre otros, conviene aludir al Convenio de la Haya, relativo a la protección del niño y a la cooperación en materia de adopción internacional, de 20 de mayo de 1993, cuyo instrumento de ratificación por parte de España fue publicado en el BOE de 1 de agosto de 1995, que regulador de la colaboración entre los distintos estados contratantes y la normativa en materia de adopción internacional, garantiza la preservación en éstas del interés del menor. También, en la Declaración de los Derechos del Niño que proclamó la Asamblea de las Naciones Unidas en su Resolución 1386, de 20 de
} 
Por cuanto atañe a las actuaciones realizadas por los distintos recursos de protección infantil, conviene precisar que presentan un marco normativo a modo de guía tanto estatal, como autonómica, diferenciándose las distintas modificaciones legislativas a nivel estatal, debido a que desde la promulgación de la CE nuestra legislación ha sufrido una constante evolución.

En primer lugar, con la Ley 21/1987, de 11 de noviembre, por la que se modifican determinados artículos del Código Civil y de la Ley de Enjuiciamiento Civil en materia de adopción, se regula dentro de las medidas de protección infantil, la institución del acogimiento familiar, incorporándose al ámbito civil una figura que hasta entonces únicamente se encontraba regulada por normas administrativas. Por tanto, se instaura un

noviembre de 1959 -principios 2, 4 y 6-, se recoge de forma explícita lo que habían sido declaraciones más genéricas al especificar que «todos los niños, con independencia de su raza, color, sexo, idioma, religión, origen nacional o social, posición económica o cualquier otra condición gozarán de los derechos recogidos en la Declaración» y, en su principio sexto prevé que "siempre que sea posible, el niño deberá crecer al amparo y bajo la responsabilidad de sus padres y, en todo caso, en un ambiente de afecto y seguridad moral y material», recogiéndose en la Resolución del Consejo de Europa (77) 33, sobre Acogimiento de Menores, de 3 de noviembre de 1977, los principios por los que debe regirse este recurso. Además, lo anterior ha sido proclamado como principios, de una parte, por la Declaración Universal de los Derechos Humanos, de 10 de diciembre de 1948, al establecer que «la maternidad y la infancia tienen derecho a cuidados y asistencia especiales». De otra, por la Convención sobre los Derechos del Niño, adoptada por la Asamblea General de las Naciones Unidas el 20 de noviembre de 1989, cuyo instrumento de ratificación por España fue publicado en el BOE de 30 de noviembre de 1990, que completa y precisa los principios establecidos por la Declaración de los Derechos del Niño, aprobada por la Asamblea de las Naciones Unidas, el 20 de noviembre de 1959, comprometiéndose los Estados a: Satisfacer las necesidades básicas de la infancia, proporcionando a los menores atención sanitaria, educación, formación [...]; Proteger a los niños contra toda forma de crueldad, explotación, maltrato, pena de muerte [...]; Ayudar a las familias, respetando sus derechos y responsabilidades y creando servicios de atención a la infancia para que atiendan convenientemente las necesidades de los hijos; Permitir al niño expresar su opinión en los asuntos que le conciernen, profesar su religión [...] todo ello en función de su edad y madurez y, por último, la Constitución Española de 1978, que en su artículo 39 recoge la protección que dispensa tanto a la familia, como al menor. Si bien, el precepto que sigue la línea respecto al interés en esta materia reflejado en los distintos acuerdos internacionales obliga a los poderes públicos a asegurar una protección a la familia como marco idóneo donde se desarrolla el individuo y donde debe ser atendido. Asimismo, se prevé la necesidad por parte de los poderes públicos a asegurar una protección al menor más allá del deber asistencial que tienen los padres con respecto a los hijos [art. $39.2 \mathrm{CE}$ ]. De forma tal, que los menores gozan de una protección tanto a través de los progenitores, como de los distintos mecanismos establecidos por los organismos públicos competentes en materia de asistencia y protección al menor y, además establece de forma expresa que «los niños gozarán de la protección prevista en los acuerdos internacionales que velan por sus derechos» [art. 39.4 CE]. También la mejor doctrina se ha pronunciado a tal respecto. Así, ROSSER LIMIÑANAprecisa que, con la LOPJM, se proclama en su artículo segundo «la primacía del interés superior de los menores sobre cualquier otro interés legítimo que pudiera concurrir» (op. cit., p. 260), En idénticos términos, se ha pronunciado (POYATOS GARCÍA, A. "Historia y evolución del acogimiento familiar de menores y el contexto de la Comunidad Valenciana», TS nova: trabajo social y servicios sociales, número 5 , 2012, p. 24). Por su parte, AMORÓS y PALACIOSsubrayan que tanto la LO 1/1995, de 15 de enero, como su antecesora -Ley 21/1987, de 11 de noviembre, de Reforma del Código civil y de la Ley de Enjuiciamiento Civil en materia de Adopción y de otras formas de protección de menores-, ponen su énfasis en la protección de los menores ante situaciones de desamparo («Acogimiento familiar», Alianza-Ensayo, Madrid, 2004, pp. 15 a 17). 
nuevo sistema de protección de menores que configura a las Entidades Públicas como elementos esenciales del nuevo sistema.

No obstante, aunque con dicha Ley no se estableció modalidad alguna en esta institución, lo cierto es que se introdujeron grandes cambios en el ámbito de la protección del menor. De modo que, se permite la asunción automática por parte de la entidad pública de la tutela de los menores que se encontraran en situación de desamparo -posibilidad que, hasta entonces, únicamente era potestad del Juez-; se considera el acogimiento familiar como una nueva institución de protección; se regulariza y simplifica el procedimiento, modificándose los artículos 172 y ss., CC y, se define esta institución como: aquella situación en la que el menor de edad obtiene la plena participación en la vida de la familia acogedora, teniendo ésta las obligaciones de velar por él, tenerlo en su compañía, alimentarlo, educarlo y procurarle una formación integral -obligaciones coincidentes con algunos deberes que son inherentes al ejercicio de la patria potestad-.

En suma, esta Ley supuso un cambio radical de toda la acción social a favor de la protección del menor que hasta la fecha se venía realizando; regula la figura del acogimiento familiar y, la define como la prioritaria frente a la institucionalización imperante hasta ese momento.

Con posterioridad, la Ley Orgánica 1/1996, de 15 de enero, de Protección Jurídica del Menor, de modificación parcial del Código Civil y de la Ley de Enjuiciamiento Civil (LOPJM), cubre algunas lagunas que quedaron pendientes por Ley 21/1987, de 11 de noviembre y, da respuesta a las nuevas necesidades y demandas suscitadas desde la publicación de la anterior, abordando de forma más adecuada la protección de la infancia. Dentro de estas novedades, destacan:

De una parte, diferencia de forma explícita el acogimiento familiar del residencial como distintas formas de ejercer la guarda de menores. De otra, define los distintos tipos y modalidades, ampliándose con ello las posibilidades de que el acogimiento familiar cubra las diversas necesidades de los menores flexibilizándose con ello la acogida familiar y, dándose respuesta a las distintas circunstancias que concurren sobre el menor $y$, a la finalidad del acogimiento y, por último, se posibilita a la Entidad Pública para acordar un acogimiento provisional del menor de forma inmediata en la familia, aun cuando los padres no consientan o se opongan y, en tanto, se origine la resolución judicial.

Téngase presente que, hasta la aprobación de la LOPJM, sin el consentimiento de los progenitores la única solución factible quedaba circunscrita al acogimiento residencial, mientras se esperaba la decisión judicial. De forma tal, que con dicha modificación legislativa la espera puede transcurrir en acogimiento provisional, evitándose con ello la necesidad de 
la estancia en hogares, lo que es de suma utilidad para el caso de los niños de menor edad, es decir, los más pequeños ${ }^{22}$.

En suma, con la Ley 21/1987, de 11 de noviembre, se regula el acogimiento familiar, enmarcado en la prioridad de que los menores carentes de un ambiente familiar adecuado reciban cuidados sustitutivos en el marco de otra familia y, no necesariamente en un centro de menores. Mientras que, con la LOPJM, se desarrolla la iniciativa del legislador en el marco anterior ampliando las posibilidades del acogimiento mediante modalidades nuevas, facilitando su aplicación $y$, se conciben las necesidades de los menores como el eje fundamental de sus derechos y protección.

Recientemente, y con la finalidad de mejorar los instrumentos de protección jurídica de la infancia y adolescencia, así como con la pretensión de constituir un referente para las Comunidades Autónomas en el desarrollo de su respectiva legislación en la materia, se ha realizado una reforma que se encuentra integrada por dos normas: la Ley 26/2015, de 28 de julio, y la Ley Orgánica 8/2015, de 22 de julio -ambas de modificación del sistema de protección a la infancia y a la adolescencia-.

Convirtiéndose España con esta nueva normativa España en el primer país que incorpora la defensa del interés superior del menor como principio interpretativo, derecho sustantivo y norma de procedimiento, como ya había sido recomendado por la Organización de Naciones Unidas en 2013.

En este sentido, las medidas más destacadas y establecidas como principios rectores, se han concretado en: la configuración un nuevo sistema de protección de la infancia; en la agilización de los procedimientos de acogimiento -en nuestro país existe un elevado número de menores bajo tutela o guarda de las administraciones, de los que gran parte de ellos se encuentran en residencias a la espera de una familia- $y$, sobre todo en la priorización del acogimiento familiar por encima del residencial -lo que resulta preceptivo en caso de menores de 6 años, debido a que se ha prescindido de la intervención judicial-.

En relación con la priorización del acogimiento familiar por encima del residencial, LÓPEZ AZCONA, precisa que «requiere de una valoración muy positiva, ya no sólo porque se adecúa al art. 9 Convención sobre los Derechos del Niño de 20 noviembre 1989 -ratificada por España el 30 noviembre 1990-, sino porque además acoge la opinión generalizada de los expertos que consideran el acogimiento familiar como más beneficioso para el menor, en cuanto garantiza su derecho a la convivencia familiar y evita su institucionalización. Es más, esta preferencia del legislador estatal por el acogimiento familiar -que el Preámbulo de la Ley 26/2015 califica de "ambiciosa", aunque ya se encontraba presente en la normativa autonómica de protección de menores- se reitera en el art. 21.3 LOPJM, refiriéndola

\footnotetext{
${ }^{22}$ En este sentido, AMORÓS y PALACIOS, sostienen que, con la LOPJM, las personas menores de edad son concebidas como "sujetos activos, participativos y creativos, con capacidad para modificar su propio medio personal y social; de participar en la búsqueda y satisfacción de sus necesidades y en la satisfacción de las necesidades de los demás» (op. cit., p. 71).
} 
especialmente a los menores de seis años, siguiendo así la recomendación que en su momento hizo de "lege ferenda" la Comisión especial del Senado de estudio de la problemática de la adopción nacional y otros temas afines»" ${ }^{23}$.

De forma que con esta normativa se agiliza el procedimiento de acogimiento favoreciendo a estos menores, debido a que ahora permanecen con una familia sin la necesidad de tener que pasar por un centro de acogida y, en caso de pluralidad de hermanos, se propugna por la necesidad de que permanezcan unidos.

Además, téngase presente que se ha desjudicializado el proceso, de forma que ya no es necesario el consentimiento de la familia biológica para proceder a la elección de la familia acogedora, sino que ahora es la propia Administración la que decide dónde debe ser acogido el menor, evitándose con ello que los menores permanezcan en centros.

Adicionalmente, conviene precisar que se simplifica la constitución del acogimiento familiar, de forma tal, que no resulta preceptiva la intervención de un Juez y, además, respecto de las familias acogedoras se introduce la necesidad de su valoración de adecuación, definiéndose a tal efecto los criterios necesarios para ello, así como se ha creado un Estatuto del Acogedor Familiar, donde se encuentran recogidos sus derechos y obligaciones.

Por otra parte, ahora los supuestos de acogimiento familiar han quedado concretados en "acogimiento de urgencia" (para menores de 6 años con una duración no superior a 6 meses), "acogimiento temporal" (máximo dos años y se resolverá si el menor vuelve con sus padres o se decide una medida más estable, como la adopción) y "acogimiento permanente" (se constituirá pasados los dos años de acogimiento temporal y cuando no sea posible la reintegración familiar o, para casos de menores con necesidades especiales, si las circunstancias lo aconsejan) y, finalmente, y por su importancia, se regula el ingreso del menor en centros de protección específicos, para el supuesto de menores que presenten problemas de conducta.

En definitiva, con estas nuevas normativas se agilizan los procesos de acogimiento; se mejora la atención a la infancia en riesgo y a menores víctimas de violencia y, se garantiza la especial protección de los menores en todo el Estado respondiendo a sus concretas necesidades.

\section{MODALIDADES DE ACOGIMIENTO}

En la actualidad y a nivel estatal la medida del acogimiento familiar se encuentra regulada en los artículos 173 y 173 bis CC. Este régimen jurídico ha sido completado por diversos legisladores autonómicos en las respectivas normas de protección de menores. De

\footnotetext{
${ }^{23}$ "Luces y sombras del nuevo marco jurídico en materia de acogimiento y adopción de menores: a propósito de la Ley Orgánica 8/2015 y la Ley 26/2015 de modificación del sistema de protección a la infancia y adolescencia», Boletín de información del Ministerio de Justicia, año LXX, número 2185, enero, 2016, p. 16.
} 
forma tal, que en aquellos supuestos en los que sea conveniente adoptar una medida de protección que comporte la separación del menor de su familia, tras la declaración de la situación de desamparo y asumida la tutela por la Administración, ésta podrá acordar el acogimiento. Posibilitándose con ello, la integración del menor en un ambiente familiar familia extensa o en ajena- $y$, de ahí que el acogimiento familiar tenga carácter preferente respecto al residencial o institucional ${ }^{24}$.

Asimismo, esta medida que no comporta que en todos los supuestos resulte la más conveniente, ha sido prevista por nuestro legislador como una alternativa el acogimiento residencial. No obstante, en función de las necesidades y circunstancias personales y familiares que presente cada menor la Administración deberá recurrir a una u otra medida, debido a que las necesidades y las condiciones en que se encuentra cada menor son diferentes y, por tanto, las medidas de protección a adoptar a cada caso concreto también lo son, ya que como algunos autores ${ }^{25}$ arguyen «lo que es bueno para un menor puede no serlo para otro».

A mayor abundamiento, conviene precisar que el acogimiento familiar produce la plena participación del menor en la vida de la familia acogedora quedando ésta obligada a asumir las funciones de contenido personal inherentes a la guarda que corresponden a la Administración como titular de la tutela.

En este sentido, el CC establece que: «El acogimiento familiar produce la plena participación del menor en la vida de familia e impone a quien lo recibe las obligaciones de velar por él, tenerlo en su compañía, alimentarlo, educarlo y procurarle una formación integra en un entorno afectivo" [art. 173. 1 CC]. Por tanto, la Administración colaborará con la persona o familia acogedora en el cumplimiento de las mencionadas funciones y controlará su debido ejercicio, a la par, que aquélla colaborará con ésta en el desarrollo del plan de actuación y mejora previsto $y$, en el funcionamiento del régimen de visitas establecido con la familia de origen.

Por su parte, la jurisprudencia menor también se ha pronunciado a tal respecto. En este sentido, el Auto de la Audiencia Provincial de Madrid, Núm. 694/2002, Sección 24. a de 04 de julio de 2002 [Roj: AAP M 1326/2002] prevé que el acogimiento consiste «en la incorporación del menor a una familia sin pasar a ser miembro de ella jurídicamente -como ocurre con la adopción-, ni dejar de serlo de la propia, pero sí integrándose de forma plena en la vida de aquella como miembro suyo más, debiendo quien lo acoge velar por él, tenerlo

\footnotetext{
${ }^{24}$ Así, PALMA DEL TESO, A. «Administraciones públicas y protección de la infancia, en especial, estudio de la tutela administrativa de los menores desamparados», Ed. Instituto Nacional de Administración Pública (INAP), Madrid. 2006, p. 374.

${ }^{25}$ Así, LÓPEZ SÁNCHEZ, F. et al. "Actuaciones frente a los malos tratos y el desamparo de menores», Centro de Publicaciones del Ministerio de Asuntos Sociales, Madrid, 1995, p. 129.
} 
en su compañía, educarle y procurar al acogido una formación integral» ${ }^{26}$.

Por otra parte, esta medida no supone de forma general la ruptura del menor con su propia familia, debido a que los menores tienen derecho a relacionarse con sus progenitores, aunque éstos no ejerzan la patria potestad, con la salvedad de que se disponga otra cosa por resolución judicial o por la Entidad Pública para los supuestos previstos por el artículo 161 CC[art. 160. 1 CC],añadiéndose a lo anterior el hecho de que al menor que forme parte de ciertas minorías se le reconocerá el derecho a tener su propia vida cultural, a profesar y practicar su religión y, a utilizar su idioma.

Así, se ha previsto por la Convención sobre los Derechos del Niño, de 20 de noviembre de 1989, al establecer que: «En los Estados en que existan minorías étnicas, religiosas o lingüísticas o personas de origen indígena, no se negará a un niño que pertenezca a tales minorías o que sea indígena el derecho que le corresponde, en común con los demás miembros de su grupo, a tener su propia vida cultural, a profesar y practicar su propia religión, o a emplear su propio idioma» [art. 30 CDN].

De forma que, las Administraciones públicas en el momento de decidir la medida de protección más idónea para el menor, deberán tener en cuenta la diversidad cultural que, con relación con la composición familiar y prácticas de crianza y formación, caracterizan a una determinada comunidad ${ }^{27}$.

Asimismo, en determinados casos como pone de manifiesto PALMA DEL TESO, cabe la posibilidad de que la propia Administración establezca en la misma resolución -por la que se acuerda el acogimiento familiar- un régimen de visitas del menor con sus padres, parientes o allegados, pudiendo además, organizar las visitas de forma que las personas acogedoras puedan asistir a éstas, evitándose con ello los posibles recelos suscitados de la familia biológica del menor hacia estas personas y permitiéndose a los padres u otros responsables del menor observar pautas de comportamiento y de relación adecuada. Además, precisa que "es fundamental que la Administración que tenga encomendada la tutela controle $y$, en su caso intervenga, para que la familia acogedora no tenga conductas de apropiación del menor, ni dificulte la relación con su familia» ${ }^{28}$.

En este sentido, se puede puntualizar que en caso de existir familiares o personas cercanas al entorno del menor, la Administración deberá facilitar y promover el acogimiento a su favor, siempre que esta medida sea la más conveniente para el menor, y para el supuesto de decantarse por el acogimiento en familia ajena será necesario que en la resolución administrativa de forma expresa se establezcan las razones por las que se

\footnotetext{
${ }^{26}$ En idéntico sentido, entre otros, el Auto de la Audiencia Provincial de Madrid, Núm. 801/2004, Sección 24. a , de 12 de noviembre de 2004 [Roj: AAP M 9851/2004]; la Sentencia de la Audiencia Provincial de Madrid, Núm. 290/2005, Sección 24. a , de 14 de julio de 2004 [Roj: SAP M 8958/2005] y, el Auto de la Audiencia Provincial de Madrid, Núm. 75/2009, Sección 22. a , de 27 de febrero de 2009 [Roj: AAP M 2899/2009].

${ }^{27}$ LÓPEZ SÁNCHEZ, op. cit., p. 55.

${ }^{28}$ Op. cit., p. 376.
} 
acuerda dicha medida y los motivos por los que no se ha considerado conveniente el acogimiento en familia extensa. De forma tal, que se deberá acordar la aplicación de la medida de acogimiento y, a la par, determinar cuál es el tipo más conveniente para el menor.

De esta forma, nuestro Ordenamiento Jurídico contempla diversos tipos de acogimiento: De una parte, en función del vínculo del menor con la familia acogedora, la medida podrá constituirse en familia ajena o extensa, de otra, en función de la duración y objetivos del acogimiento, podrá ser urgente, temporal o permanente $y$, finalmente $y$, en función del tipo de la familia acogedora se prevé la posibilidad del acogimiento familiar especializado.

En definitiva, el acogimiento familiar se configura como una forma de protección al menor, inspirada su regulación en el principio superior del interés del menor; se prevé para aquellos supuestos en los que el menor se encuentra privado de un ambiente familiar idóneo, teniendo presente la temporalidad de éste hasta que se origine la reinserción del menor en su familia biológica -cuando cesen las causas que originaron esta situación- 0 , se constituya su tutela 0 , sea posible su adopción y, además es destacable al tratarse de una medida de carácter temporal y revocable.

Como ya se ha anunciado en líneas previas, en la actualidad, el acogimiento familiar se encuentra en función de distintos criterios integrados por diversos tipos. En este sentido, aunque nuestro legislador con Ley 21/1987, de 11 de noviembre, introdujo esta institución en nuestro Derecho, lo cierto es que lo realizó con una regulación parca, debido a que no estableció ninguna modalidad en orden a una diferenciación de sus clases.

De forma tal, que será con posterioridad y, atendiendo a una demanda doctrinal, a través de la LOPJM, cuando con la Disposición Final Séptima se introduzca el artículo 173 bis en el CC, estableciéndose con ello y, de forma expresa, las distintas modalidades de acogimiento en función de su finalidad. Y más recientemente, con Ley 26/2015, de 28 de julio, de modificación del sistema de protección a la infancia y a la adolescencia, se ha redactado ex novo el mencionado precepto pudiéndose, en la actualidad, adoptar en función de su duración y objetivos las modalidades siguientes: De una parte, el acogimiento urgente, de otra, el acogimiento temporal y, finalmente, el acogimiento permanente.

No obstante, téngase presente que estas modalidades que son de aplicación concreta a cada menor en función de su situación previa; la de su familia y, la decisión que adopte la entidad pública o el Juez, amplían de forma considerable la cobertura de las diversas necesidades requeridas por los menores.

En este sentido, MORENO FLÓREZ, matiza que «la situación que determina que respecto de un menor se constituya un acogimiento puede tener su origen, bien como medio corrector de los problemas que tiene el menor en su entorno familiar, que habrán desembocado en una situación de desamparo o, como medio al que se recurre cuando ese 
menor carece de la necesaria asistencia por causas no imputables a sus progenitores y éstos han solicitado su guarda de la entidad pública» ${ }^{29}$.

Por su parte, EGEA FERNÁNDEZ, señala que «puede hacerse una subdistinción, según lo que se persiga, ya sea simplemente la convivencia en familia que supla las necesidades elementales, con vistas a un posible retorno a la familia originaria o, bien se conciba como un periodo de prueba para la adopción ${ }^{30}$.

\section{1. Modalidades de acogimiento familiar en relación con las características de la familia acogedora y la vinculación del menor con la familia acogedora}

En este sentido, dos son las modalidades de acogimiento familiar, de una parte, el acogimiento en familia extensa del menor $y$, de otra, el acogimiento en familia ajena, resultando preferente el primero de ellos, tal y como se desprende del artículo 20. 2 LOPJM al precisar que "se valorará la adecuación de la edad de los acogedores con la del menor acogido, así como la relación previa entre ellos, priorizando, salvo que el interés del menor aconseje otra cosa, a las personas que, perteneciendo a su familia extensa, reúnan condiciones adecuadas para el acogimiento». También, la mejor doctrina ${ }^{31}$ se ha pronunciado en idéntico sentido al precisar que lo más aconsejable es que el acogimiento familiar se constituya a favor de algún miembro de la familia extensa del menor.

De esta forma, tanto la jurisprudencia menor, como algunas legislaciones autonómicas $^{32}$, han puesto de manifiesto que la Administración acordará preferentemente

\footnotetext{
${ }^{29}$ "Acogimiento Familiar», 1. a ed., Ed. Dikynson, Madrid, 2012, p. 45.

${ }^{30}$ "Comentarios a los artículos 173-174 CC; Artículos 63.16; 1825-1828 LEC y Disposición Adicional 2. ${ }^{\text {a. En }}$ Comentarios a las reformas del Código civil. Desde la Ley 21/1987, de 11 de noviembre, a la Ley 30/1991, de 20 de diciembre, (Coordinador Rodrigo Bercovitz Rodríguez-Cano), Ed. Tecnos, Madrid, 1993, p. 104.

${ }^{31}$ Vid., SÁINZ-CANTERO CAPARRÓS, M.a B y PARDO MARTÍNEZ, E. «Régimen jurídico de los centros de protección y reforma de menores», Ed. Comares, Granada, 2010, p. 139.

${ }^{32}$ Así, entre otras, la Ley $1 / 1995$, de 27 de enero, de Protección del Menor del Principado de Asturias, en su artículo 44 letra c), establece: «Favorecer la permanencia del menor en su propio ambiente, procurando que el acogimiento se produzca en su familia extensa, salvo que no resultase aconsejable en orden al interés primordial del menor»; la Ley $3 / 2011$, de 30 de junio, de apoyo a la familia y a la convivencia de Galicia, en su artículo 69 letra c) precisa: "Favorecer la permanencia del niño, niña o adolescente en su propio ambiente, procurando que el acogimiento se produzca en familia extensa, salvo que no fuera aconsejable para el interés de la persona menor acogida o de las o los menores del grupo familiar acogedor»; la Ley Foral 15/2005, de 5 de diciembre, de promoción, atención y protección a la infancia y a la adolescencia de Navarra, en su art. 69 letra a) dice que se: «Favorecerá la permanencia del menor en su propio ambiente, procurando el acogimiento con la familia extensa, salvo que tal medida no resulte aconsejable para los intereses del menor». También la Ley 1/2006, de 28 de febrero, de Protección de Menores de La Rioja, en su art. 75. 1 letra b), prevé el: «Mantenimiento del menor en su propio entorno, prefiriendo en lo posible el acogimiento en familia extensa del menor o en favor de personas con quien éste hubiera sostenido previamente relaciones positivas, siempre que su interés resulte así salvaguardado"; el Decreto 282/2002, de 12 de noviembre, de Acogimiento Familiar y Adopción de la Junta de Andalucía, en su art. 33 dice que:"El acogimiento, simple o permanente, en familia ajena procederá cuando no sea posible el acogimiento en la familia extensa del menor bien por inexistencia de parientes interesados en su constitución o por falta de idoneidad de éstos». Asimismo, en la Ley 8/2010, de 23
} 
el acogimiento en familia extensa, siempre que existan familiares o, personas interesadas e idóneas para ello y, que tengan una especial relación con el menor y, para el caso de solicitud por familiares a los que la Administración les excluya la posibilidad del acogimiento en familia extensa se deberán expresar las razones.

En esta línea, en la Sentencia de la Audiencia Provincial de Valencia, Núm. 213/2003, Sección 10.a , de 16 de abril de 2003 [Roj: SAP V 2502/2003] que "debe darse preferencia a la familia biológica como lugar de normal desarrollo del menor, que deben agotarse los recursos existentes en ayudas a la familia biológica, y que debe razonarse debidamente por la Administración por qué se excluye el acogimiento en la familia extensa ${ }^{33}$.

En este punto, el DEFENSOR DEL PUEBLO DE ESPAÑ ${ }^{34}$, precisó que habría sido aconsejable que el legislador estatal hubiese establecido una noción legal de familia extensa, en defecto de un concepto unitario sobre ésta en la legislación autonómica. De modo que, el legislador autonómico, mientras que en algunos casos acoge un concepto estricto, como sería, por ejemplo, en el artículo 8. 1 del Decreto 40/2006, de 21 de abril, por el cual se regulan los procedimientos de acogimiento familiar, de adopción y de determinación de idoneidad de les Illes Balears, al precisar que: «A los efectos de este Decreto se entiende por familia extensa el núcleo de personas que tienen relaciones de parentesco con el menor hasta el cuarto grado. Por tanto, el acogimiento familiar simple en familia extensa se constituye cuando las personas acogedoras del menor formen parte de su entorno familiar más próximo hasta este cuarto grado de parentesco» -quedando circunscrito de esta forma únicamente a los parientes del menor-, por el contrario, en otros defiende un concepto amplio, como sería en el artículo 127. 2 de la Ley 14/2010, de 27 de mayo, de los derechos y las oportunidades en la infancia y la adolescencia de Cataluña, al establecer que: "A los efectos de la presente ley, se entiende por familia extensa aquella en la que existe una relación de parentesco por consanguinidad o afinidad entre el niño o el adolescente y la persona acogedora, o uno de los miembros de la familia acogedora, así como con los convivientes con el niño o el adolescente en los últimos dos años», debido ello a que da idéntico rango a aquellas personas que tengan una especial vinculación con el menor.

de diciembre, de garantía de derechos y atención a la infancia y la adolescencia de Cantabria, en su art. 37.4 precisa que: "En los casos orientados a un acogimiento familiar, se valorará en primer lugar la opción del acogimiento en familia extensa, siempre que se trate de personas que hayan mantenido vínculos afectivos con la persona menor. Si esta opción responde a su interés y necesidades, será preferente a su acogimiento en familia ajena» y, en la Ley 5/2014, de 9 de octubre, de Protección Social y Jurídica de la Infancia y la Adolescencia de Castilla-La Mancha, en su art. 76. 2 establece que: «Para favorecer la reintegración familiar se dará preferencia para ser acogedores a los miembros de la familia extensa o las personas con una previa y positiva relación con el menor, siempre que demuestren suficiente capacidad y disponibilidad para su atención y desarrollo integral».

${ }^{33}$ En idéntica línea, entre otros, el Auto de la Audiencia Provincial de Valencia, Núm. 224/2001, Sección 10. a , de 08 de noviembre de 2001 [Roj: AAP V 687/2001]; el Auto de la Audiencia Provincial de Valencia, Núm. 301/2006, Sección 10. a, de 18 de mayo de 2006 [Roj: SAP V 1356/2006].

${ }^{34}$ "Centros de protección de menores con trastorno de conducta y en situación de dificultad social. Informes, estudios y documentos», Ed. Defensor del Pueblo, Madrid, 2009, p. 52. 
También, la Comunidad Valenciana ${ }^{35}$ sigue de cerca a la catalana, en el sentido de que, aunque considera como familia extensa a las personas que tienen una relación de parentesco con el menor, lo cierto es que asimila a ésta a las personas vinculadas con el menor o su familia por una especial y cualificada relación.

Es decir, que mientras algunas normas autonómicas la restringen a parientes hasta tercer grado ${ }^{36}$, otras la refieren a los parientes sin límite de grado ${ }^{37} \mathrm{e}$, incluso, hay algunas que la extienden a no parientes, siempre que tengan una especial vinculación con el menor $^{38}$.

También el artículo 173 bis. $1 \mathrm{CC}^{39}$ y el artículo 20. 1. Párrafo 2.ㅇ LOPJM ${ }^{40}$, han incorporado la posibilidad ya prevista por algunas legislaciones autonómicas de que el acogimiento en familia ajena sea especializado, en función de las características que presentan los menores y, a su vez, éste podrá ser profesionalizado ${ }^{41}$ cuando «reuniendo los

\footnotetext{
${ }^{35}$ Así, el art. artículo 46. 2 letra a) del Decreto 93/2001, de 22 de mayo, del Gobierno Valenciano, por el que se aprueba el Reglamento de Medidas de Protección Jurídica del Menor en la Comunidad Valenciana, precisa: "Acogimientos familiares en familia extensa, son aquellos que se formalizan con personas vinculadas con el menor por una relación de parentesco, siendo su objetivo evitar que éste se desvincule afectivamente de su entorno familiar, manteniéndolo en el mismo. Se asimilan a estos acogimientos aquellos formalizados con personas vinculadas con el menor o con su familia por una especial y cualificada relación».

${ }^{36}$ En este sentido, el artículo 3. 2 del Decreto 282/2002, de 12 de noviembre, de Acogimiento Familiar y Adopción de la Junta de Andalucía, precisa que: "A los efectos previstos en este Decreto, se entenderá por familia extensa aquélla en la que existe una relación de parentesco por consanguinidad o por afinidad hasta de tercer grado, entre el menor y los solicitantes del acogimiento. Se entenderá por familia ajena aquélla con la que no exista la relación de parentesco antes referida».

${ }^{37}$ Cfr., artículo 127. 2 de la Ley 14/2010, de 27 de mayo, de los derechos y las oportunidades en la infancia y la adolescencia de Cataluña.

${ }^{38}$ Así, el artículo 116. 2 de la Ley 12/2008, de 3 de julio, de la Generalitat, de Protección Integral de la Infancia y la Adolescencia de la Comunitat Valenciana, prevé que: «El acogimiento familiar, en sus modalidades de simple y permanente, podrá distinguirse, en razón de la vinculación de la familia o persona acogedora y el menor, en acogimientos familiares en familia extensa, aquellos que se formalizan con personas vinculadas al menor o su familia por una relación de parentesco o por una especial y cualificada relación afectiva, y en acogimientos familiares con familia educadora, aquellos que se formalizan con personas sin vinculación alguna con el menor» y, Vid., también en esta línea el artículo 24 del Decreto 108/2007, de 27 de julio, por el que se aprueba el Reglamento sobre intervención de las Administraciones Públicas de La Rioja en la protección y guarda de los menores y, los artículos. 101 y ss., del Decreto 190/2008, de 7 de octubre, del Gobierno de Aragón, por el que se aprueba el Reglamento de medidas de protección de menores en situación de riesgo o desamparo.

39 Dice el precepto: «El acogimiento familiar podrá tener lugar en la propia familia extensa del menor o en familia ajena, pudiendo en este último caso ser especializado».

${ }^{40}$ El mencionado artículo prevé que: «El acogimiento en familia ajena podrá ser especializado, entendiendo por tal el que se desarrolla en una familia en la que alguno de sus miembros dispone de cualificación, experiencia y formación específica para desempeñar esta función respecto de menores con necesidades o circunstancias especiales con plena disponibilidad y percibiendo por ello la correspondiente compensación económica, sin suponer en ningún caso una relación laboralı.

${ }^{41}$ En las legislaciones autonómicas el acogimiento profesionalizado, es definido, entre otras, por el artículo 66. 2 de la Ley 1/1997, de 7 de febrero, de Atención Integral a los Menores de Canarias, como: "aquel en que la persona o familia que acoge en su núcleo familiar a uno o varios menores recibe una cantidad mensual por su labor y por los gastos de alimentación y educación del menor o menores acogidos» y, además, precisa en su
} 
requisitos de cualificación, experiencia y formación específica, exista una relación laboral del acogedor o acogedores con la Entidad Pública» [art. 20. 1. párr. 3.o LOPJM].

En este sentido, LÓPEZ AZCONA, precisa que este acogimiento se configura como "aquel que se desarrolla en una familia en la que alguno de sus miembros dispone de formación específica para desempeñar esta función con plena disponibilidad respecto de menores con necesidades o circunstancias especiales ${ }^{42}$, es decir, como un recurso destinado a ofrecer un ambiente familiar a menores que presenten necesidades especiales o requieran de una atención especializada.

Este sería el caso, por ejemplo, de grupos de hermanos o menores con discapacidades físicas, psíquicas o sensoriales o enfermedades crónicas o, como PALMA DEL TESO, dice "menores próximos a la mayoría de edad»" ${ }^{43}$. Por tanto, su finalidad se concreta en facilitar la integración familiar, evitándose con ello su derivación al acogimiento residencial. Quedando excluidos como LÓPEZ AZCONA -con acierto- precisa "los menores con problemas de conducta, a los que se reserva el acogimiento residencial en centro especializado» ${ }^{44}$.

apartado primero, que: «El acogimiento familiar simple y el permanente podrán constituirse con carácter profesionalizado». También, los apartados 1 y 2 del artículo 48 de la Ley 3/1999, de 31 de marzo, del Menor de Castilla- La Mancha, respectivamente, establecen que: «El acogimiento familiar simple y el permanente podrán constituirse con carácter profesionalizado" y, que: «Se entiende por acogimiento profesionalizado aquel que se ejerce por una persona especialmente cualificada que acoge en su núcleo familiar a uno o varios menores $y$ recibe una cantidad por su labor y por los gastos de alimentación y educación del menor o menores acogidos». En los mismos términos, el artículo 82. 1 de la Ley 1/2006, de 28 de febrero, de Protección de Menores de La Rioja, precisa que: "El acogimiento familiar simple y el permanente podrán ejercerse con carácter profesionalizado, cuando recaigan en persona o personas especialmente cualificadas que acogen en su núcleo familiar a uno o varios menores y reciben una cantidad por su labor y por los gastos de alimentación y educación del menor o menores acogidos». Y, también se recoge su definición por el artículo 10. 2 del Decreto 40/2006, de 21 de abril, por el cual se regulan los procedimientos de acogimiento familiar, de adopción y de determinación de idoneidad de les Illes Balears, al prever que: «El acogimiento profesionalizado es aquél que se constituye con personas que por su formación ostenten la cualificación necesaria para atender el cuidado de un menor con especiales necesidades». Asimismo, el SENADO, en sus Recomendaciones números 66, 67 y 68, del Informe especial de la Comisión Especial de Estudio de la problemática de la adopción nacional y otros temas afines, previó, de una parte, el «Reconocimiento del acogimiento profesionalizado, entendido como el realizado por aquellas familias que hacen del acogimiento su principal actividad profesional y perciben por ello una remuneración económica», de otra, el "Reconocimiento del acogimiento especializado, entendido como el realizado por aquellas familias que tienen una cualificación y formación especial para abordar el acogimiento de niños con problemas de salud, discapacidad, trastornos de conducta u otros, y que reciben una compensación para suplir los gastos ocasionados con el acogimiento» y, finalmente, el "Reconocimiento de las modalidades de acogimiento especializado como el acogimiento terapéutico para casos de menores con graves problemas asociados a distintas patologías médicas» (Boletín Oficial de las Cortes Generales, IX Legislatura, Serie I: Boletín General, número 545, de 17 noviembre 2010, p. 53).

${ }^{42}$ Op. cit., p. 37.

${ }^{43}$ Op. cit., p. 383.

${ }^{44}$ Op. cit., p. 37. 
Este acogimiento, en todo caso, es remunerado, sin que ello implique una relación laboral entre la Administración y el acogedor, es decir, que: «El acogimiento en familia ajena podrá ser especializado, entendiendo por tal el que se desarrolla en una familia en la que alguno de sus miembros dispone de cualificación, experiencia y formación específica para desempeñar esta función respecto de menores con necesidades o circunstancias especiales con plena disponibilidad y percibiendo por ello la correspondiente compensación económica, sin suponer en ningún caso una relación laboral» [art. 20. 1. párr. 2.o LOPJM].

$\mathrm{Y}$, en consecuencia, de existir tal relación laboral, se atribuye al acogimiento especializado el carácter de profesionalizado. Así: «El acogimiento especializado podrá ser profesionalizado cuando, reuniendo los requisitos anteriormente citados de cualificación, experiencia y formación específica, exista una relación laboral del acogedor o los acogedores con la Entidad Pública» [art. 20. 1. párr. 3. LOPJM], posibilidad ésta ya contemplada en el antiguo artículo 173. 2. 2. 6. CC.

Así, PALMA DEL TESO, arguye que "el carácter profesional del acogimiento y la formación del acogedor es una garantía de que la familia no se apropiará del menor ${ }^{45}$. Por su parte, otros autores ${ }^{46}$, precisan que en general, los padres, tutores o familiares no tendrán respecto a estas personas el recelo que habitualmente sienten frente a una familia acogedora tradicional.

En suma, las finalidades que presenta esta figura caracterizada por su carácter remunerado, son: garantizar al menor acogido sus necesidades materiales; permitir el acceso al acogimiento a personas o familias con pocos recursos; contar con personas cualificadas que en contacto con el menor desarrollan un plan de mejora en colaboración con la Administración y, preparar al menor por el acogedor para el retorno con su familia biológica, así como facilitar las relaciones familiares, siendo posible la presencia del acogedor en las visitas.

\section{2. Modalidades del acogimiento familiar en atención a su duración y objetivos}

\section{2. 1. El acogimiento de urgencia}

Esta modalidad de acogimiento ha sido incorporada con la pretensión de que fuese circunscrita a los menores de seis años y con una duración limitada a seis meses, mientras se decide la medida de protección a adoptar ${ }^{47}$.

En este sentido, MAYOR DEL HOYO ${ }^{48}$ precisa que tendrá especial importancia este tipo de acogimiento en los supuestos previstos por el artículo 172.4 CC, en los que la

\footnotetext{
${ }^{45}$ Op. cit., p. 384.

${ }^{46}$ Vid., LÓPEZ SÁNCHEZ, op. cit, pp. 14-15.

${ }^{47}$ En este sentido, SENADO. op. cit., pp. 49 y 52.
} 
entidad pública, en atención al cumplimiento de la obligación de prestar atención inmediata asume la guarda provisional de un menor mediante resolución administrativa, pero también podrá utilizarse en aquellos casos en los que la Entidad Pública haya asumido la guarda del menor por haberse arrogado bien una tutela administrativa [art. $172.1 \mathrm{CC}$ ] bien una guarda administrativa [art. 172 bis CC], cuando la Entidad Pública necesite un tiempo para decidir qué medida resulta oportuna para ese menor, o cuando, por la razón que sea $y$, una vez decidida la medida, no se pueda constituir el acogimiento temporal permanente. Y, LÓPEZ AZCONA establece que también "esta modalidad de acogimiento ya se practicaba en algunas CC.AA., en particular, respecto de los menores de tres años, según información proporcionada por sus servicios sociales» ${ }^{49}$.

\section{2. 2. El acogimiento temporal}

Esta modalidad de acogimiento, que hasta la reforma se denominaba acogimiento simple $^{50}$, se encuentra caracterizado por la transitoriedad o provisionalidad $y$, justificado en aquellos supuestos en que el menor se halle necesitado, quedando circunscrita su finalidad a

\footnotetext{
${ }^{48}$ "Sistema tuitivo del menor en el Código civil español: acogimiento y otras medidas de protección». En El acogimiento y otras medidas de protección de la infancia y adolescencia desamparada, Ed. Universitat de Lleida, 2012, p. 903.

${ }^{49}$ Op. cit., p. 35.Asimismo, el SENADO, en su Recomendación número 69, del Informe especial de la Comisión Especial de Estudio de la problemática de la adopción nacional y otros temas afines, sugería la necesidad de impulsar el acogimiento de urgencia, ya recogido en algunas CC.AA especialmente para bebes menores de tres años, previa coordinación entre las CC. AA para crear una bolsa de acogedores en todo el Estado para estos acogimientos de urgencia y, fijar un cuidadoso sistema de formación, valoración y apoyo a dichas familias de urgencia (op. cit., p. 53). Y en la Recomendación número 46, ponía de manifiesto la necesidad de "Establecer plazos de duración del acogimiento en función de los objetivos perseguidos con el mismo; así, distinguir entre el acogimiento breve, para bebés, con una duración de hasta seis meses; y el acogimiento simple, con una duración de hasta dos años, en función de la edad del menor (hasta los seis años, con una duración inferior a un año; y en los demás casos, con una duración de entre 12 y 24 meses, asegurando, en todo caso, que a los 18 meses esté tomada la decisión sobre el futuro del menor)» («Informe especial de la Comisión Especial de Estudio de la problemática de la adopción nacional y otros temas afines» (op. cit., p. 52). LÓPEZ SAN LUIS, R. dispone que: "En algunas Comunidades Autónomas como Andalucía ya se venían realizando el acogimiento familiar de urgencia. Esta modalidad de acogimiento es una medida que se aplica a menores sobre los que hay que intervenir de forma inmediata, evitando la institucionalización temprana y favoreciendo que gocen de un ambiente y atención familiar durante el tiempo necesario para realizar el estudio sobre la situación del/la menor y proponer bien la vuelta con su familia de origen, o la medida de protección más adecuada. Para llevar a cabo esta medida de protección las instituciones públicas cuentan con familias que de manera inmediata y con total disponibilidad pueden hacerse cargo del/la menor ante una situación de desprotección concreta. Esta medida de protección es de corta duración y suele aplicarse a menores de muy corta edad (de 0 a 6 años). El acogimiento familiar de urgencia tiene una duración mínima de 6 meses, prorrogables por otros 3, y es remunerado en todos los casos» («La regulación del acogimiento tras las últimas reformas legislativas en materia de protección a la infancia y a la adolescencia en el derecho español», Revista Chilena de Derecho y Ciencia Política, Vol. 7, número 2, 2016, pp. 47-100, pp. 80-81).

${ }^{50}$ En este sentido, téngase presente que, la Disposición adicional segunda de la Ley 26/2015, de 28 de julio, de modificación del sistema de protección a la infancia y a la adolescencia, precisa que: «Todas las referencias que en las leyes y demás disposiciones [...] que se realizasen al acogimiento simple deberán entenderse hechas al acogimiento familiar temporal previsto en el artículo 173 bis del Código Civil [...]».
} 
proporcionarle protección mientras decae la situación provisional que lo originó, lo que podría tener lugar, bien por su reinserción en su familia de origen o, bien por la adopción de una media de protección que revista un carácter más estable y que antes no era factible, como sería el caso del acogimiento familiar permanente o, incluso, de la adopción ${ }^{51}$.

Por tanto, este carácter transitorio permite que la Administración proceda a su constitución cuando se prevea que la situación de desamparo es de carácter temporal, de modo que esta medida se constituye como PALMA DEL TESO, precisa acertadamente en «un hito en el camino hacia una situación más estable ${ }^{52}$.

En síntesis, se trata de una modalidad de duración breve, cuya finalidad queda reducida al retorno del menor a su familia de origen tras la superación de la situación que originó el problema y, en consecuencia, su constitución únicamente será posible cuando sea previsible la reinserción familiar del acogido a corto plazo.

Como ya se ha mencionado en líneas previas, se trata de una medida de carácter transitorio, pero esta reforma presenta como novedad la limitación legalmente establecida a una duración máxima de dos años que podrán ser prorrogables en atención al interés del menor, siguiéndose con ello la Recomendación número 46 del SENADO ${ }^{53}$, en el Informe especial de la Comisión Especial de Estudio de la problemática de la adopción nacional y otros temas afines, concretada, en que ésta tuviese una duración entre doce y veinticuatro meses para el caso de acogimientos de mayores de seis años, mientras que, para los supuestos de menores de seis años, propugnaba por que se limitase el acogimiento a un año.

BERROCAL LANZAROT, precisa que "este acogimiento tendrá una duración máxima de dos años, salvo que el interés superior del menor aconseje la prórroga de la medida por la previsible e inmediata reintegración familiar o la adopción de otra medida de protección definitiva -plazo de tiempo que coincide con el de la guarda administrativa asumida a solicitud de los padres o tutores [art. 172 bis CC]; o con el cese de la suspensión y revocación de la declaración de desamparo [art. 172.2 CC]» ${ }^{54}$.

Además, y de conformidad con lo establecido por el artículo 303. 1 apartado 2.0 in fine CC se podrá constituir este tipo de acogimiento cuando haya una situación de guarda de hecho, nombrando a los guardadores como acogedores. Punto, en el que la mejor doctrina ${ }^{55}$

\footnotetext{
${ }^{51}$ Vid., BERROCAL LANZAROT, A. I. «La guarda y tutela administrativa de menores. El acogimiento familiar y residencial». En La protección jurídica de la infancia y la adolescencia tras la Ley Orgánica 8/2015, de 22 de julio y la Ley 26/2015, de 28 de julio, (Coordinadores Ana Isabel Berrocal Lanzarot y Carmen Callejo Rodríguez), WoltersKluwer España. La Ley, 2017, p. 205.

${ }^{52}$ Op. cit., p. 377.

${ }^{53}$ Op. cit., p. 52.

${ }^{54}$ "La guarda y tutela administrativa..., op. cit., p. 206.

${ }^{55}$ MAYOR DEL HOYO, M. a V. «Comentario a los artículos 173, 173 bis y 174 del Código Civil». En Código Civil comentado, vol. I, (directores Ana Cañizares Laso, Pedro de Pablo Contreras, Javier Ortuña Moreno y Rosario Valpuesta Fernández), 2.a ed., Ed. Civitas, Thomson Reuters, Cizur Menor, Navarra, 2016, p. 906.
} 
suele considerar como idóneos para este tipo de acogimiento familiar a la familia extensa del menor, es decir, a los abuelos, a los tíos [...].

Por otra parte $y$, respecto al acogimiento familiar temporal como un modo de reintegración o retorno del menor en su familia de origen, conviene precisar que resulta innegable, que se trata de una medida de carácter estable, debido a que el menor es acogido por una familia y, de forma simultánea, se prevé la realización de un plan de mejora que permita la reintegración de éste a su entorno socio-familiar, de modo que, mientras dura el acogimiento continúa manteniendo sus relaciones con su familia biológica ${ }^{56}$.

En el ámbito estatal, el CC prevé en atención a su duración y objetivos, diversas modalidades de acogimiento. En este sentido, el texto legal establece que «tendrá carácter transitorio, bien porque de la situación del menor se prevea la reintegración de éste en su propia familia, o bien en tanto se adopte una medida de protección que revista un carácter más estable como el acogimiento familiar permanente o la adopción. [...]» [art. 173 bis. 2. b) $\mathrm{CC}$.

En esta línea, se ha pronunciado la Jurisprudencia menor. Así, en la Sentencia de la Audiencia Provincial de Madrid, número 324/2011, Sección 22.a , de 29 de abril de 2011 [LEX354760410], se define el acogimiento como «aquella situación temporal y revocable, orientada a la protección de los menores que se encuentran privados -aunque sea circunstancialmente- de una adecuada atención familiar $y$, consiste en confiar al menor al cuidado de personas que reúnan las condiciones morales y materiales necesarias para proporcionarle el sustento, habitación, vestido y especialmente, una vida familiar conforme con los usos sociales- El acogimiento produce la plena participación en la vida de la familia e impone a quien le recibe las obligaciones de velar por él tenerlo en su compañía, alimentarlos, educarlo y procurarle una formación integral» ${ }^{57}$.

En definitiva, se puede concluir que, se trata de una medida transitoria que, ni es definitiva ni vinculante y que, en la actualidad, se encuentra limitada a una duración de dos años que puede ser prorrogable en atención al interés del menor.

\footnotetext{
${ }^{56}$ En idéntico sentido, vid., PALMA DEL TESO, op. cit., p. 378.

${ }^{57}$ Vid., en idéntico sentido, entre otros, el Auto de la Audiencia Provincial deCantabria, número 398/2002, Sección 1. a , de 24 de septiembre de 2002 [Roj: AAP S 257/2002]; Auto de la Audiencia Provincial de Tenerife, número 123/2008, de 26 de mayo de 2008 [Roj: AAP TF 1919/2008]; Auto de la Audiencia Provincial de Guadalajara, número 51/2003, Sección 1. a , de 30 de mayo de 2003 [Roj: AAP GU 104/2003]; la Sentencia de la Audiencia Provincial de Bikaia, número 820/2017, Sección 4.a , de 27 de diciembre de 2017 [Roj: SAP BI 2506/2017]; la Sentencia de la Audiencia Provincial de León, número 75/2017, Sección 2. a , de 13 de marzo de 2017 [Roj: SAP LE 300/2017] y, la Sentencia de la Audiencia Provincial de Guadalajara, número 295/2013, Sección 1. a , de 28 de enero de 2014 [Roj: SAP GU 29/2014].
} 


\section{2. 3. El acogimiento permanente}

El acogimiento familiar permanente se encuentra reservado para aquellos supuestos de carácter prolongado en los que no queda otra alternativa para el menor, es decir, para aquellas situaciones en las que resulta imposible tanto la reintegración del menor en su familia, como su adopción. Las causas que originan esta medida, entre otras, son: la elevada edad del menor; la existencia de problemas físicos o psíquicos o, de actitudes de comportamiento que dificulten su adopción [...].

En este sentido, se prevé para situaciones en que por las circunstancias o características que presenta el menor, resulta aconsejable una integración familiar estable, pero sin creación de vínculo de filiación. De ahí que haya sido calificada por la doctrina ${ }^{58}$ como una especie de cajón de sastre para aquellos menores a los que resulta imposible aplicarles otros tipos de acogimiento familiar. $Y$, en consecuencia, se encuentre previsto únicamente para casos en los que no proceda la adopción, independientemente, de que se prevea o no el retorno del menor a su familia de origen a medio o largo plazo.

Así, MAYOR DEL HOYO ${ }^{59}$, argumenta que este carácter permanente no significa que se trate de una medida definitiva o irreversible, en cuanto cesa con la adquisición de la mayor edad e, incluso, con anterioridad, si el interés del menor así lo demanda. Por tanto, el término permanente sería sinónimo del vocablo estable, pero no de irreversible. $Y$, además, este autor precisa que sus efectos son los propios del acogimiento, con la única salvedad de que la Entidad Pública puede solicitar del Juez que atribuya a los acogedores aquellas facultades de la tutela que puedan facilitar el desempeño de sus responsabilidades y, en su caso, la representación del menor.

También, LINACERO DE LA FUENTE, señala que "se trata de una medida que, únicamente, será aplicable cuando no exista posibilidad de retorno del menor con su familia de origen y cuando no sea posible iniciar el proceso para su adopción o tutela ordinaria, siendo por tanto aconsejable su integración de forma estable y duradera en la familia acogedora sin necesidad de crear vínculos de filiación ${ }^{60}$.

Por su parte, POYATOS GARCÍA, argumenta que «son acogimientos que se caracterizan porque el retorno no es posible o deseable; al tiempo que la adopción no resulta posible o aconsejable. Este tipo de acogimiento suele durar hasta la mayoría de edad o, hasta que se encuentre una alternativa más idónea para el niño o niña ${ }^{61}$.

Por tanto $y$, de conformidad, con la redacción del nuevo texto contenido en el precepto la constitución de esta medida tendrá lugar en dos supuestos, de una parte,

\footnotetext{
${ }^{58}$ Vid., en este sentido, las aportaciones de PALMA DEL TESO, op. cit., p. 379 y, CAPARROS CIVERA, N y JIMÉNEZAYBAR, I. «El acogimiento familiar: aspectos jurídicos y sociales», Ed. Rial, Madrid, 2001, p. 76.

${ }^{59}$ "Sistema tuitivo..., op. cit., pp. 51-68.

${ }^{60}$ «Protección jurídica del menor», Ed. Montecorvo, Madrid, 2001, p. 306.

${ }^{61}$ Op. cit., p. 26.
} 
"cuando las circunstancias del menor y su familia así lo aconsejen" y, en particular, cuando el menor acogido tenga necesidades especiales. De otra, cuando finalice el acogimiento temporal "por no ser posible la reintegración familiar" ${ }^{62}$. Supuesto último en el que se faculta a la Administración a "solicitar del Juez que atribuya a los acogedores permanentes aquellas facultades de la tutela que faciliten el desempeño de sus responsabilidades, atendiendo, en todo caso, al interés superior del menor ${ }^{63}$ [art. 173 bis. 2. c) CC] -cuya previsión que ya se encontraba recogida en idénticos términos en el antiguo precepto [art. 173 bis. párr. 3. CC]-, ampliándose con ello el contenido del ejercicio del acogimiento no solo al ámbito personal ${ }^{64}$, sino también al ámbito patrimonial y de representación de menor.

En este sentido, FLUITERS CASADO, establece que "esta posibilidad solo procedería cuando la Entidad pública hubiese asumido la tutela por Ministerio de Ley, ya que de

\footnotetext{
${ }^{62}$ En este sentido, BERROCAL LANZAROT, precisa que: "Se constituirá bien al finalizar el plazo de dos años de acogimiento temporal por no ser posible la reintegración familiar, o bien directamente en casos de menores con necesidades especiales o cuando las circunstancias del menor y su familia así lo aconsejen». ( LLa guarda y tutela administrativa..., op. cit., p. 206). Por su parte, MAYOR DEL HOYO, dice que: "la posibilidad de recurrir directamente a este acogimiento en los casos de guarda administrativa es inexistente porque resulta contraria a la institución» y, añade que "cuando se busca una medida estable, se recurrirá a esta medida cuando, o no resulte aconsejable $o$, no se pueda constituir la adopción" y, concluye que "puede decirse que este acogimiento permanente cumple una importante función de reintegración familiar estable de menores que por su situación tienen más difícil el acceso a la misma» («Comentario a los artículos 173..., op. cit., p. 892).

${ }^{63}$ En este sentido, BERROCAL LANZAROT, nos recuerda que «el antiguo artículo 173 bis del Código Civil contemplaba tres modalidades de acogimiento familiar: simple, preadoptivo y permanente. El acogimiento familiar simple está, al igual que, el acogimiento familiar temporal actual caracterizado por la nota de la transitoriedad. así, tal acogimiento familiar simple obedecía a los supuestos en que era seguro o previsible que, la guarda concluiría con la reinserción del menor en su propia familia, al haber tenido lugar por un desamparo motivado por razones coyunturales o guarda asumida de modo transitorio por la entidad pública a solicitud de los padres (antiguo artículo 173 bis 1 del Código Civil); o, también como recurso provisional hasta que se tomar una decisión sobre la asunción de una media de carácter más estable para el menor -adopción o la constitución de la tutela ordinaria-. No se establecía plazo, a diferencia de la regulación actual, donde el acogimiento familiar temporal tendrá una duración máxima de dos años, salvo que el interés superior del menor determine la necesidad de una prórroga de la medida por la inmediata o previsible reintegración en la familia de origen o la adopción de otra medida de protección definitiva. En cuanto al antiguo acogimiento familiar permanente tenía lugar ante el carácter definitivo de las circunstancias que motivaron el desamparo no hacían posible la reinserción del menor en su familia, y sin que, además fuera conveniente la adopción para el menor - por su edad avanzada. De ahí, la exigencia de un acogimiento más estable y desprovisto de la nota de transitoriedad. Sin embargo, en la actual regulación se adoptará tal acogimiento cuando finalice el plazo de dos años de acogimiento temporal y no sea posible la reintegración en la familia de origen, o en los casos de menores con necesidades especiales o cuando la situación del menor y su familia así lo aconsejen». ("La «revitalización» de la guarda de hecho tras la Ley 26/2015, de 28 de julio de modificación del sistema de protección a la infancia y a la adolescencia (I)», Revista Crítica de Derecho Inmobiliario, número 757, 2016, p. 2867.)

${ }^{64}$ Así, el artículo 66. 3 de la Ley 1/2006, de 28 de febrero, de Protección de Menores de La Rioja, establece que: "Se favorecerá el mantenimiento y fomento de los vínculos fraternales, cualquiera que sea la medida de protección acordada, procurando la convivencia de los hermanos».
} 
contrario podría integrar una privación de facto de la patria potestad o tutela, cuando ésta no es la finalidad del acogimiento ${ }^{65}$.

Con la incorporación de esta medida por nuestro legislador al CC, de una parte, se solventan algunas de las cuestiones que quedaron pendientes en modificaciones legislativas previas, siendo éstas: a quién le corresponde la representación del menor acogido; la administración de sus bienes $\mathrm{y}$, el poder de decisión en los aspectos fundamentales en la vida del menor ${ }^{66} \mathrm{y}$, de otra, su aplicabilidad queda circunscrita a la totalidad de CC. AA, debido a que éstas se encuentran carentes de competencia alguna en materia de legislación civil para regularla por sí mismas.

En definitiva, la calificación de este tipo de acogimiento, de una parte, permite que se prolongue, en principio, hasta la mayoría de edad del menor, cesando de forma automática [art. 173. 4 letra d) CC], de otra, que se constituya un régimen de visitas a favor de los progenitores y demás parientes $\mathrm{y}$, finalmente, requiere que conste en el documento del anexo a la resolución administrativa la duración que está prevista para éste [art. 20. 3 letra c) LOPJMJ].

\section{IDONEIDAD PARA SER ACOGEDORES}

Con la modificación legislativa realizada por Ley 26/2015, de 28 de julio, de una parte, se establecen los criterios que la Administración debe tener presente para valorar la adecuación (o no) de la familia para el acogimiento familiar, es decir, que se tendrá en cuenta su situación familiar y aptitud educadora, su capacidad para atender adecuadamente las necesidades de toda índole del menor o menores de que se trate, la congruencia entre su motivación y la naturaleza y finalidad del acogimiento según su modalidad y, la disposición a facilitar el cumplimiento de los objetivos del plan individual de atención o, del programa de reintegración familiar, propiciándose con ello la relación del menor con su familia de procedencia, de conformidad con lo establecido por la legislación autonómica de protección de menores, de otra, cuando el tipo de acogimiento así lo aconseje, se valorará la adecuación de la edad de los acogedores con la del menor acogido, así como la relación previa entre ellos, priorizando, salvo que el interés del menor aconseje otra cosa, a las personas que, perteneciendo a su familia extensa, reúnan las condiciones adecuadas para el acogimiento [art. 20. 2 LOPJM]. Y, por último, se declarará la inhabilidad para ser acogedores de aquéllos que no puedan ser tutores [art. 172 ter. 1. párr. 2.ำ CC].

Por tanto, la concurrencia de alguna de las causas legales de inhabilidad previstas en sede de tutela inhabilitará a la persona o familia de que se trate para el acogimiento familiar. Siendo estas causas, las siguientes: De una parte, las contenidas en el artículo 243 CC: "No pueden ser tutores: 1. Los que estuvieran privados o suspendidos en el ejercicio de la patria

\footnotetext{
${ }^{65}$ "Acogimiento y adopción», Cuadernos de Derecho Judicial, número 16, 1996, p. 304.

${ }^{66}$ Vid., LINACERO DE LA FUENTE, op. cit., pp. 283-286 y, DIEZ GARCÍA, H. «El acogimiento familiar simple como una de las formas de ejercer la guarda de menores», Ed. Ministerio de Trabajo y Asuntos Sociales, Madrid, 2004, pp. 90-95.
} 
potestad o total o parcialmente de los derechos de guarda y educación, por resolución judicial. 2. Los que hubieren sido legalmente removidos de una tutela anterior. 3. Los condenados a cualquier pena privativa de libertad, mientras estén cumpliendo la condena. 4. Los condenados por cualquier delito que haga suponer fundadamente que no desempeñarán bien la tutela». Y, de otra, las establecidas en el art. 244 CC: "Tampoco pueden ser tutores: 1. Las personas en quienes concurra imposibilidad absoluta de hecho. 2.․ Los que tuvieren enemistad manifiesta con el menor o incapacitado. 3. Las personas de mala conducta o que no tuvieren manera de vivir conocida. 4. Los que tuvieren importantes conflictos de intereses con el menor o incapacitado, mantengan con él pleito o actuaciones sobre el estado civil o sobre la titularidad de los bienes, o los que le adeudaren sumas de consideración. 5. Los quebrados y concursados no rehabilitados, salvo que la tutela lo sea solamente de la persona».

De lo anterior, se observa que aunque múltiples son los motivos a que los que puede responder esta inhabilitación, como sería el caso, entre otros, por ejemplo, de: la falta de preparación o de condiciones para el cargo, la falta de confianza, la falta de recursos económicos, la conducta inapropiada, los intereses incompatibles [...], lo cierto es que todas estas causas tienen como pretensión apartar del cuidado y de los bienes del menor o incapacitado a aquéllos que se encuentren incursos en cualquiera de ellas, dándose con ello prioridad al interés de la persona protegida.

En consecuencia, los acogedores que no incurran en las causas previstas en líneas previas podrán ser valorados en relación con su posible o no adecuación para el desempeño de sus funciones por la Administración, la que tomará como pauta los criterios mencionados en el artículo 20. 2 LOPJM, es decir, la situación familiar y la aptitud educadora de los acogedores, su capacidad para atender a las necesidades de los menores, la congruencia entre su motivación y la naturaleza del acogimiento, su disposición a facilitar el cumplimiento de los objetivos del plan individual de atención y, en su caso, el programa de reintegración familiar, su edad y su relación previa ${ }^{67}$. Criterios que son coincidentes con los previstos por la legislación autonómica ${ }^{68}$.

\footnotetext{
${ }^{67}$ Así, vid., SAINZ-CANTERO CAPARRÓS, B. «El modelo común para la intervención con menores en riesgo y desamparo propuesto por el Anteproyecto de Ley de Protección de la infancia», Revista de Derecho Civil, vol. I, número 4 (octubre-diciembre), 2014, p. 142.

${ }^{68}$ Por cuanto atañe a los criterios establecidos por la legislación autonómica en relación con la valoración y selección de acogedores, entre otros, el artículo 84 de la Ley 1/2006, de 28 de febrero, de protección de menores de La Rioja, prevé que: «1. Los acogedores serán seleccionados en función del interés primordial del menor, considerando, entre otros factores, la aptitud educadora, la situación familiar, la relación previa con el menor y los demás criterios de idoneidad que se establezcan reglamentariamente, en atención tanto a la modalidad como a la finalidad del acogimiento. 2. Para favorecer la reintegración familiar y evitar el desarraigo del menor, tendrán preferencia para ser acogedores los miembros de su familia extensa o las personas con una previa y positiva relación con el menor, siempre que demuestren suficiente capacidad y disponibilidad para su atención y desarrollo integral. 3. Los acogedores profesionales y los responsables de los hogares funcionales habrán de contar, previamente a la formalización del acogimiento, con la declaración de idoneidad para el desempeño de sus labores. 4. En el acogimiento preadoptivo, los acogedores habrán de
} 


\section{CONSTITUCIÓN DEL ACOGIMIENTO FAMILIAR}

En este sentido, conviene precisar que la constitución administrativa del acogimiento familiar [art. 20. 2 LOPJM] ha supuesto la supresión de la constitución judicial para el supuesto de oposición o, de incomparecencia de los progenitores o tutor ordinario -prevista en el antiguo artículo 172. 3. párrafo 1. CC-, justificándose lo anterior en el interés de los menores [Preámbulo de la Ley 26/2015, de 28 de julio].

En este sentido, TOSCANO GIL, precisa que "tampoco se puede afirmar que en sede administrativa los procedimientos de constitución del acogimiento familiar se tramiten siempre con la suficiente celeridad, lo que obedece en muchas ocasiones a las deficiencias de

contar con una previa declaración de idoneidad, y serán seleccionados según los criterios de valoración previstos para la adopción»; el artículo 76 de la Ley 5/2014, de 9 de octubre, de Protección Social y Jurídica de la Infancia y la Adolescencia de Castilla-La Mancha, dice que: «1. Además del interés superior del menor, los acogedores serán seleccionados en función de su aptitud educadora, su situación familiar, la relación previa con el menor y demás criterios de idoneidad que se determinen reglamentariamente en atención tanto a la modalidad como a la finalidad del acogimiento. 2. Para favorecer la reintegración familiar se dará preferencia para ser acogedores a los miembros de la familia extensa o las personas con una previa y positiva relación con el menor, siempre que demuestren suficiente capacidad y disponibilidad para su atención y desarrollo integral. 3. En los casos de acogimientos familiares especializados o ejercidos en hogares funcionales se requiere la declaración de idoneidad que corresponda a cada uno, en los términos que se establezcan reglamentariamente»; el artículo 46 de la Ley 1/1995, de 27 de enero, de protección del menor del Principado de Asturias, establece que: «1. Los acogedores serán seleccionados con arreglo al interés primordial del menor, teniendo en cuenta, entre otros factores, la aptitud educadora, la situación familiar, la relación con el menor, si existiese y, en todo caso, la capacidad de relación con el mismo, la edad y otras circunstancias que habrán de ser objeto de desarrollo reglamentario, con la única excepción del acogimiento familiar administrativo en el que sean los padres, tutores o guardadores del menor quienes señalen unos acogedores determinados. 2. Los acogimientos que no tengan como finalidad la adopción dará preferencia a familiares o acogedores de hecho, siempre que demuestren suficiente capacidad para la atención y desarrollo integral del menor»; el artículo 61 de la Ley 1/1997, de 7 de febrero, de Atención Integral a los Menores de Canarias, precisa que: «1. Los acogedores serán seleccionados con arreglo al interés primordial del menor, teniendo en cuenta, entre otros factores, la aptitud educadora, la situación familiar, la relación con el menor, si existiese, y los demás criterios de idoneidad que se establezcan reglamentariamente, en atención tanto a la modalidad como a la finalidad del acogimiento. 2. En los acogimientos en familia, con la finalidad de favorecer la reintegración familiar y evitar el desarraigo del menor, tendrán preferencia para ser acogedores los miembros de la familia extensa del mismo, 0 sus guardadores de hecho cuando estén unidos a éste o a su familia por una especial y cualificada relación y demuestren tener aptitudes para la atención y desarrollo integral del menor. 3. En los acogimientos en hogar funcional, el responsable o responsables del mismo deberán ser previamente declarados idóneos para el desempeño de sus labores, a solicitud de la entidad colaboradora titular del hogar. 4. En los acogimientos con finalidad preadoptiva, los acogedores serán seleccionados con arreglo a los criterios de valoración previstos para la adopción»; el artículo 47. 2 de la Ley 3/1999, de 31 de marzo, del Menor de Castilla- La Mancha, dispone que: "Entre los criterios de selección se atenderá, principalmente, a la actitud educativa de los acogedores, su situación familiar, su motivación, su sensibilidad para entender la problemática de los menores y su familia, así como a cualquier otro factor que favorezca el desarrollo integral y el superior interés del menor». 
índole material y presupuestarias existentes en la Administración y no sólo en la de Justicia» ${ }^{69}$.

En suma, con esta reforma se agiliza la constitución del acogimiento en pro del menor, encontrándose la resolución administrativa sujeta a control jurisdiccional, de ahí que sea susceptible de impugnación judicial por los progenitores o por el tutor ordinario al precisarse en el CC que durante el plazo de dos años podrán oponerse a las decisiones que se adopten respecto a la protección del menor [art. 172. 2. párr. 2. CC]. Y de conformidad con la Ley de Enjuiciamiento Civil, se prevé que: «1. No será necesaria reclamación previa en vía administrativa para formular oposición, ante los Tribunales civiles, a las resoluciones administrativas en materia de protección de menores. La oposición a las mismas podrá formularse en el plazo de dos meses desde su notificación. -Estarán legitimados para formular oposición a las resoluciones administrativas en materia de protección de menores, siempre que tengan interés legítimo y directo en tal resolución, los menores afectados por la resolución, los progenitores, tutores, acogedores, guardadores, el Ministerio Fiscal y aquellas personas que expresamente la ley les reconozca tal legitimación. Aunque no fueran actores podrán personarse en cualquier momento en el procedimiento, sin que se retrotraigan las actuaciones» [art. 780 LEC].

En síntesis, se puede precisar que el legislador con esta modificación legislativa, de una parte, prescinde del consentimiento de los progenitores o del tutor ordinario, sustituyendo éste por la notificación de la resolución administrativa, siempre que no se encuentren, de forma respectiva, o privados de la patria potestad o, removido la tutela [art. 172 ter. 1. párr. 3. CC], de otra, mantiene para la válida constitución del acogimiento el consentimiento de los acogedores y del menor acogido que sea mayor de doce años o menor de doce, siempre que cuente con la madurez suficiente [art. 173. $2 \mathrm{CC}$ ] y, finalmente, permanece inalterada la exigencia de notificación al Ministerio Fiscal, lo que "resulta coherente con la función de vigilancia del acogimiento que tiene atribuida legalmente» ${ }^{70}$.

Además, a la resolución administrativa de formalización del acogimiento se le acompañará de un documento anexo que incluirá los siguientes extremos: «a) La identidad del acogedor o acogedores y del acogido. b) Los consentimientos y audiencias necesarias. c) La modalidad del acogimiento, duración prevista para el mismo, así como su carácter de acogimiento en familia extensa o en familia ajena debido a la vinculación del menor con la familia o persona acogedora. d) Los derechos y deberes de cada una de las partes, y en particular: 1. El régimen de visitas, estancia, relación o comunicación, en los supuestos de declaración de desamparo, por parte de la familia de origen, que podrá modificarse por la Entidad Pública en atención al interés superior del menor. 2. El sistema de cobertura por parte de la Entidad Pública de los daños que sufra el menor o de los que pueda causar a terceros. 3.o La asunción por parte de los acogedores de los gastos de manutención,

\footnotetext{
${ }^{69}$ "El acogimiento administrativo de menores: Análisis de su problemática en sede judicial», Actualidad Jurídica Aranzadi, número 708, 2006, p. 8.

${ }^{70}$ LÓPEZ AZCONA, op. cit., p. 28.
} 
educación y atención sociosanitaria. e) El contenido del seguimiento que, en función de la finalidad del acogimiento, vaya a realizar la Entidad Pública y el compromiso de colaboración con dicho seguimiento por parte de la familia acogedora. f) En el caso de menores con discapacidad, los recursos de apoyo que precisa. g) La compensación económica, apoyos técnicos y otro tipo de ayudas que, en su caso, vayan a recibir los acogedores. h) El plazo en el cual la medida vaya a ser revisada»[art. 20. 3 LOPJM]. A lo anterior, se incluye para el caso de menor con discapacidad los recursos de apoyo de carácter especializado que viniera recibiendo o, en su caso, la adopción de otros más adecuados a sus necesidades [art. 173. 1 $\mathrm{CC}]$.

Otro aspecto que debe tenerse presente queda circunscrito a la posibilidad de que la Administración pueda exigir a los progenitores el reembolso de los gastos que les genere la responsabilidad civil que pudiese ser imputada a los menores por la realización de sus actos $\mathrm{y}$, en este sentido, establece el precepto que: "En los casos de declaración de situación de desamparo o de asunción de la guarda por resolución administrativa o judicial, podrá establecerse por la Entidad Pública la cantidad que deben abonar los progenitores o tutores para contribuir, en concepto de alimentos y en función de sus posibilidades, a los gastos derivados del cuidado y atención del menor, así como los derivados de la responsabilidad civil que pudiera imputarse a los menores por actos realizados por los mismos»[art. 172. ter. 4 $\mathrm{CC}]$.

Asimismo, conviene puntualizar que, con la previsión concerniente a la concreción del plazo de revisión de la medida, se da cumplimiento al deber impuesto a la Administración de revisar las medidas de protección adoptadas para cada menor. Así, la revisión de cualquier medida no permanente, es decir, la de acogimientos de urgencia y temporales para el caso de menores de tres años, se revisará cada tres meses y, respecto de los mayores de esa edad se revisará cada seis meses. $Y$ para el supuesto de acogimientos permanentes la revisión tendrá lugar el primer año cada seis meses $y$, a partir del segundo año, se realizará cada doce meses[art. 12. 5 LOPJM].

En definitiva, tras la adopción de la resolución administrativa de constitución del acogimiento familiar, se deberá proceder a su notificación por la Administración: De una parte, a los progenitores -siempre que no estén privados de la patria potestad- o, al tutor ordinario, si es el caso -siempre que no esté removido de su tutela-, los cuales como ya se anunció en líneas previas ya no se encuentran llamados a prestar ni su consentimiento ni a ser oídos y, de otra, al Ministerio Fiscal.

En este sentido, se ha pronunciado, tanto el CC al establecer que: "La resolución de la Entidad Pública en la que se formalice por escrito la medida de guarda se notificará a los progenitores o tutores que no estuvieran privados de la patria potestad o tutela, así como al Ministerio Fiscal» [art. 172 ter. 1. párr. 3. CC], como la LOPJM, al prever que «La resolución y el documento anexo se remitirán al Ministerio Fiscal en el plazo máximo de un mes» [art. 20. 3 LOPJM], omitiéndose en el texto contenido en el precepto referencia alguna a los progenitores $\mathrm{o}$ al tutor a que alude el CC y, originándose con ello una duplicidad normativa, 
al ponerse de manifiesto una evidente descoordinación en la reforma realizada por Ley 26/2015, de 28 de julio.

\section{EL ESTATUTO DEL ACOGEDOR: DERECHOS Y DEBERES}

En este sentido, aunque se regula por primera vez el estatuto del acogedor familiar como un conjunto de derechos y deberes, lo cierto es que la función realizada por las familias de acogida hace conveniente que su status sea perfilado por una disposición de carácter general, precisándose lo anterior, en la Recomendación número 51 del SENADO, en el Informe especial de la Comisión Especial de Estudio de la problemática de la adopción nacional y otros temas afines, al establecer la necesidad de: "Aprobar la carta de derechos de las familias acogedoras, que reconozca su derecho a ser parte en los procedimientos judiciales que les afectan (los acogedores deben ser oídos porque son quienes mejor conocen la problemática del niño y su experiencia puede ayudar a afinar las medidas de protección); el derecho al mantenimiento de relaciones con el menor al cesar el acogimiento, si es lo mejor para el menor, cuando el acogimiento haya sido de larga duración; el derecho a una compensación económica; a recibir apoyo técnico especializado; a ser escuchado; y a acceder a la información sobre el menor que pueda ser clave para su manejo y cuidado» ${ }^{71}$.

De este modo, lo anterior ha originado que se incorpore en la LOPJM un estatuto del acogedor familiar integrado por un amplio abanico de deberes referidos bien a la Administración o, bien al menor acogido [art. 20 bis LOPJM], que ya se encontraban contemplados en su gran mayoría por la legislación autonómica ${ }^{72}$ de protección de menores.

\footnotetext{
${ }^{71}$ SENADO. op. cit., pp. 52-53.

${ }^{72}$ En relación con la legislación autonómica, entre otros, el artículo 90 del Decreto 190/2008, de 7 de octubre, del Gobierno de Aragón, por el que se aprueba el Reglamento de medidas de protección de menores en situación de riesgo o desamparo, establece que: «1. Las personas que reciban a un menor en acogimiento tienen la obligación de velar por él, tenerlo en su compañía, alimentarlo, educarlo, procurarle formación integral, y garantizar el cumplimiento de las relaciones con la familia de origen recogidas en la Resolución que acuerde el acogimiento familiar. 2. Son también obligaciones de la familia acogedora: a) Colaborar, en su caso, en la reinserción del menor en su familia de origen y favorecer su integración familiar. b) Actuar coordinadamente con los técnicos encargados del seguimiento del acogimiento, compartir con ellos la información disponible y seguir sus orientaciones. c) Respetar la confidencialidad de la información que posean, en especial la referida a los antecedentes personales y familiares del menor. d) Apoyar el proceso de autonomía personal y social del menor, dirigido a su emancipación" y, el artículo 44. 1 del Decreto Foral 7/2009, de 19 de enero, por el que se aprueba el reglamento de desarrollo parcial de la Ley Foral 15/2005, de 5 de diciembre, de promoción, atención y protección a la infancia y a la Adolescencia, que prevé: "Son obligaciones de la familia acogedora las siguientes: a) Ofrecer al menor educación, manutención, habitación, vestido, asistencia médica y, en general, el acceso a todos los programas normalizados de la comunidad y previstos en la legislación civil. b) Facilitar las relaciones periódicas con la familia natural del menor. c) Colaborar en la reinserción del menor en su familia de origen o favorecer su integración familiar. d) Actuar de forma coordinada con los profesionales encargados del seguimiento del acogimiento, compartir con ellos la información disponible y seguir sus orientaciones. e) Respetar la confidencialidad de la información que posean, en especial la referida a los antecedentes personales y familiares del menor. f) Apoyar el proceso de autonomía personal y social del menor, dirigido a su emancipación».
} 
En relación con los derechos que ostentan los acogedores en relación con la Administración, son:

1. Derecho a recibir información tanto de la naturaleza y efectos del acogimiento y, del plan individual de protección, como de las medidas de protección relacionadas con el acogimiento que se adopten respecto al menor acogido [art. 20 bis. 1 letras a) y c) LOPJM].

2. Derecho tanto a recibir apoyo técnico especializado durante y al término del acogimiento que, para el caso de menores con discapacidad, además, tendrán derecho a orientación, acompañamiento $y$ apoyo adaptados a la discapacidad del menor, como a recabar el auxilio de la Entidad Pública en el ejercicio de sus funciones[art. 20 bis. 1 letras a) y i) LOPJM].

3. Derecho a ser oídos por la Entidad Pública antes de que ésta adopte cualquier resolución que afecte al menor, es decir, al derecho de audiencia previa [art. 20 bis. 1 letra b) LOPJM]. Derecho que es de suma importancia, debido a que implica el reconocimiento del interés legítimo de los acogedores en la toma de estas decisiones, amén de la información que pueden aportar sobre el menor acogido ${ }^{73}$.

4. Derecho a ser parte en todos los procesos de oposición a las medidas de protección y a la declaración de situación de desamparo del menor acogido [art. 20 bis. 1 letra d) LOPJM]. Derecho incorporado por recomendación del CONSEJO GENERAL DEL PODER JUDICIAL ${ }^{74}$.

5. Derecho a formular formalmente quejas o sugerencias ante la Entidad Pública[art. 20 bis. 1 letra ñ) LOPJM].

6. Derecho a disponer de la documentación identificativa, sanitaria y educativa del menor que acogen[art. 20 bis. 1 letra f) LOPJM].

7. Derecho a percibir una compensación económica y otro tipo de ayuda que se hubiera estipulado[art. 20 bis. 1 letra k) LOPJM].

En este sentido, LÓPEZ AZCONA, entiende que, «el acogimiento familiar siempre tendría que estar sustentado con una ayuda económica, sea o no profesionalizado, ya no sólo por la importante implicación personal y material que conlleva para las familias de acogida, sino, ante todo, para que el propio acogimiento del menor puede desarrollarse en condiciones adecuadas» ${ }^{75}$.

\footnotetext{
${ }^{73}$ CONSEJO GENERAL DEL PODER JUDICIAL (PLENO). «Informe al Anteproyecto de Ley de protección a la infancia», 2014, p. 34.2 Disponible http://www.congreso.es/docu/docum/ddocum/dosieres/sleg/legislatura_10/spl 78/pdfs/15.pdf. [Consultado el 22 de noviembre de 2018].

${ }^{74} \mathrm{Op}$ cit., $\quad$ p. $99 . \quad$ Disponible en: http://www.congreso.es/docu/docum/ddocum/dosieres/sleg/legislatura 10/spl 78/pdfs/15.pdf. [Consultado el 22 de noviembre de 2018].

${ }^{75}$ Op. cit., p. 32.
} 
8. Derecho a la protección de sus datos personales respecto de su familia de origen[art. 20 bis. 1 letra $n$ ) LOPJM].

9. Derecho a tener idénticos derechos que la Administración reconoce al resto de unidades familiares [art. 20 bis. 1 letra o) LOPJM].

En este punto, conviene destacar la reforma a que ha sido sometido el artículo 2. 4 de la Ley 40/2003, de 18 de noviembre, de Protección a las Familias Numerosas, por Ley 26/2015, de 28 de julio, con la finalidad de extrapolar los beneficios de las familias numerosas a las familias de acogida -siempre que se trate de un acogimiento familiar permanente o pre adoptivo y, más en concreto, en caso de guarda con fines adoptivos-.

Por cuanto atañe a los derechos que ostentan los acogedores en relación con los menores, son:

1. Derecho a ejercer todos los derechos inherentes a la guarda; a ser respetados por el menor acogido y, a relacionarse con el menor al cesar el acogimiento, si la Entidad Pública entiende que es conveniente a su interés superior y lo permite la familia de origen o, en su caso, la familia adoptiva o de acogimiento permanente y, el menor si tuviere suficiente madurez $y$, en todo caso, si fuera mayor de doce años [art. 20 bis. 1 letras g); h) y, m) LOPJM].

No obstante, obsérvese que este último derecho se encuentra configurado como un derecho recíproco, debido a que también es atribuido al menor acogido [art. 21 bis. 2 letra b) LOPJM], exigiéndose el consentimiento de este último si tuviese suficiente madurez y, en todo caso, si fuese mayor de doce años y, de la familia de acogida y de la de origen o, de la familia adoptiva o de acogimiento permanente, si es el caso.

Respecto a los deberes que ostentan los acogedores en relación con la Administración, al seguir ésta ostentando la titularidad de la guarda del menor en acogimiento. Son:

1. Deber de informar a la Entidad Pública tanto de cualquier hecho de trascendencia en relación con el menor, como de cualquier cambio en la situación familiar relativo a los datos y circunstancias que se tomaron en consideración como base para el acogimiento [art. 20 bis. 2 letras d) y, h) LOPJM].

2. Deber de colaborar activamente con las Entidades Públicas en el desarrollo de la intervención individualizada con el menor y seguimiento de la medida, como en el tránsito de la medida de protección del menor a la reintegración de su familia o de otra medida de protección[art. 20 bis. 2 letras f) y, k) LOPJM].

Con esta última medida se impone a los acogedores, tanto el deber de colaborar en la reintegración del menor en su familia de origen, como -para el supuesto de imposibilidad 
de dicha medida- en la adopción de cualquier otra medida de protección, ya sea la adopción del menor $\mathrm{o}$, ya sea otra modalidad de acogimiento e, incluso, una medida diferente.

3. Deber de participar en las acciones formativas propuestas[art. 20 bis. 2 letra j) LOPJM].

Respecto a los deberes que ostentan los acogedores en relación con los menores. Son:

1. Deber de velar por el bienestar y el interés superior del menor, tenerlo en su compañía, alimentarlo, educarlo y procurarle una formación integral en un entorno afectivo. En el caso de menor con discapacidad, deberá seguir prestando los apoyos especializados que viniera recibiendo o adoptar otros más adecuados a sus necesidades. [art. 21 bis. 2 letra a) LOPJM].

2. Deber de oír al menor siempre antes de tomar decisiones que le afecten, si tuviese suficiente madurez, a transmitir a la Entidad Pública las peticiones que éste pudiese realizar dentro de su madurez[art. 20 bis. 2 letra b) LOPJM].

3. Deber de asegurar la plena participación del menor en la vida de familia y, respeto $y$ facilitación de las relaciones con la familia de origen del menor, en la medida de sus posibilidades y, en el marco del régimen de visitas establecido a favor de aquélla y la reintegración familiar[art. 20 bis. 2 letras c) y e) LOPJM].

4. Deber de respetar la confidencialidad de los datos relativos a los antecedentes personales y familiares del menor, de garantizar el derecho a la intimidad y a la identidad de los menores acogidos y, el de su propia imagen[art. 20 bis. 2 letras g) y i) LOPJM].

En definitiva, con el estatuto del acogedor y de los menores acogidos se amplía la seguridad jurídica y la cobertura legal que son necesarias para que las familias acogedoras puedan desarrollar sus funciones, con plenas garantías de sus derechos para los menores acogidos.

\section{DERECHOS DE LOS MENORES ACOGIDOS}

En este punto, convienen precisar que la LOPJM atribuye un amplio elenco de derechos de forma general a los menores con independencia de la modalidad de acogimiento en que se encuentren, provenientes gran parte de ellos de la legislación autonómica de protección de menores [art. 21 bis. 1 LOPJM]. Derechos concretados en los siguientes:

«a) Ser oído en los términos del artículo 9 y, en su caso, ser parte en el proceso de oposición a las medidas de protección y declaración en situación de desamparo de acuerdo con la normativa aplicable, y en función de su edad y madurez. Para ello 
tiene derecho a ser informado y notificado de todas las resoluciones de formalización y cese del acogimiento».

En este punto, conviene puntualizar, de una parte, que el artículo 9 LOPJM ha sido modificado por Ley Orgánica 8/2015, de 22 de julio, de modificación del sistema de protección a la infancia y a la adolescencia, con la pretensión de otorgar al derecho de audiencia del menor de una regulación que fuese conforme, con el artículo $12^{76}$ Convención sobre los Derechos del Niño. De otra, este derecho concretado en ser parte en el proceso de oposición ha sido incorporado a nuestra legislación estatal, con la pretensión de adecuarse al artículo $5^{77}$ del Instrumento de Ratificación del Convenio Europeo sobre el Ejercicio de los Derechos de los Niños, hecho en Estrasburgo el 25 de enero de 1996 -ratificado por España el 11 noviembre 2014-, conforme a las recomendaciones realizadas tanto por el DEFENSOR DEL PUEBLO DE ESPAÑ $A^{78}$, como por el CONSEJO GENERAL DEL PODER JUDICIAL en el Informe al Anteproyecto de Ley de protección a la infancia ${ }^{79}$. Y finalmente, el derecho a ser informado y notificado de todas las notificaciones de cese o formalización del acogimiento también se incorpora siguiendo las recomendaciones realizadas en su día por el CONSEJO GENERAL DEL PODER JUDICIAL, en el mencionado informe ${ }^{80}$.

«b) Ser reconocido beneficiario del derecho de asistencia jurídica gratuita cuando se encuentre en situación de desamparo».

Téngase presente que en este supuesto deberá encontrarse bajo la tutela de la administración, mientras que cuando esté bajo la guarda administrativa no tendrá cabida tal derecho, aunque sí se cubrirán, bien por sus progenitores -si no han sido suspendidos de la patria potestad- o, bien por su tutor los gastos que se hayan derivado de su asistencia jurídica.

\footnotetext{
${ }^{76}$ El precepto establece que: «1. Los Estados Partes garantizarán al niño que esté en condiciones de formarse un juicio propio el derecho de expresar su opinión libremente en todos los asuntos que afectan al niño, teniéndose debidamente en cuenta las opiniones del niño, en función de la edad y madurez del niño. 2. Con tal fin, se dará en particular al niño la oportunidad de ser escuchado en todo procedimiento judicial o administrativo que afecte al niño, ya sea directamente o por medio de un representante o de un órgano apropiado, en consonancia con las normas de procedimiento de la ley nacional».

77 Dice el precepto que: "Las Partes examinarán la oportunidad de conceder a los niños derechos procesales complementarios en los procedimientos que les afecten ante una autoridad judicial, en particular: a. el derecho a solicitar la asistencia de una persona apropiada de su elección con el fin de que les ayude a expresar su opinión; b. el derecho a solicitar por sí mismos o a través de otras personas u organismos la designación de un representante distinto $y$, en los casos oportunos, de un abogado; c. el derecho a nombrar su propio representante; d. el derecho a ejercitar en todo o en parte los derechos de las partes en dichos procedimientos». ${ }^{78}$ Op. cit., p. 44.

${ }^{79}$ Op. cit., $\quad$ p. $\quad 99 . \quad$ Disponible en: http://www.congreso.es/docu/docum/ddocum/dosieres/sleg/legislatura 10/spl 78/pdfs/15.pdf. [Consultado el 22 de noviembre de 2018].

${ }^{80}$ Op. cit., $\quad$ p. $47 . \quad$ Disponible en: http://www.congreso.es/docu/docum/ddocum/dosieres/sleg/legislatura_10/spl 78/pdfs/15.pdf. [Consultado el 22 de noviembre de 2018].
} 
También este derecho fue incorporado a nuestra legislación, tras las recomendaciones efectuadas, tanto por el DEFENSOR DEL PUEBLO DE ESPAÑ ${ }^{81}$ como por el MINISTERIO DE SANIDAD, SERVICIOS SOCIALES E IGUALDAD ${ }^{82}$ en el Anteproyecto de ley de modificación del Sistema de Protección a la Infancia y a la Adolescencia.

«c) Dirigirse directamente a la Entidad Pública y ser informado de cualquier hecho trascendente relativo al acogimiento.

d) Relacionarse con su familia de origen en el marco del régimen de visitas, relación y comunicación establecido por la Entidad Pública».

Derecho entendido en relación con lo establecido por el artículo 161 CC, que habilita a la Entidad Pública para regular las visitas y comunicaciones que correspondan a los progenitores, abuelos, hermanos y demás parientes y allegados respecto a los menores declarados en situación de desamparo, pudiéndose acordar de forma motivada la suspensión temporal del régimen de visitas y comunicaciones en interés del menor.

Asimismo, el artículo 20. 3 letra d) LOPJM incluye dentro de los extremos que debe contener el documento anexo a la resolución administrativa del acogimiento familiar: «1.․ $\mathrm{El}$ régimen de visitas, estancia, relación o comunicación, en los supuestos de declaración de desamparo, por parte de la familia de origen, que podrá modificarse por la Entidad Pública en atención al interés superior del menor».

Lo anterior pone fin a las polémicas suscitadas en relación con la instancia que debía ser competente para fijar y modificar el régimen visitas de los menores acogidos.

En relación con la posible suspensión temporal del régimen de visitas [art. 161 CC], conviene precisar que ésta únicamente se podrá adoptar por la Administración con previa audiencia de los afectados y del menor si tuviese suficiente madurez y, en todo caso, si fuera mayor de doce años, con inmediata notificación al Ministerio Fiscal.

Por último, conviene precisar que el precepto recoge la posibilidad de oposición a las resoluciones administrativas que hayan recaído sobre estas cuestiones $y$, para ello otorga legitimación al menor acogido; a los afectados y, al Ministerio Fiscal.

Lo anunciado en líneas previas, será de aplicabilidad únicamente a los menores declarados en desamparo y, por tanto, que se encuentren bajo la tutela de la administración, omitiéndose referencia alguna a los menores que se encuentren bajo guarda administrativa, por lo que, la competencia en relación con las visitas con su familia de origen seguirá atribuida a la autoridad judicial [art. 160 CC].

\footnotetext{
${ }^{81}$ Op. cit., p. 405.

${ }^{82}$ SANIDAD, SERVICIOS SOCIALES E IGUALDAD. "Anteproyecto de ley de modificación del Sistema de Protección a la Infancia y a la Adolescencia». Consejo de Estado: Dictámenes. Referencia: 1093/2014, Fecha de aprobación: 27/11/2014. Disponible en: https://www.boe.es/buscar/doc.php?id=CE-D-2014-1093\&lang=en [Consultado el 21 de noviembre de 2018].
} 
«e) Conocer progresivamente su realidad socio-familiar y sus circunstancias para facilitar la asunción de las mismas.

f) Recibir con la suficiente anticipación la información, los servicios y los apoyos generales que sean necesarios para hacer efectivos los derechos de los menores con discapacidad.

g) Poner en conocimiento del Ministerio Fiscal las reclamaciones o quejas que considere, sobre las circunstancias de su acogimiento.

h) Recibir el apoyo educativo y psicoterapéutico por parte de la Entidad Pública, para superar trastornos psicosociales de origen, medida esta aplicable tanto en acogimiento residencial, como en acogimiento familiar.

i) Recibir el apoyo educativo y psicoterapéutico que sea necesario y.

j) Acceder a su expediente y conocer los datos sobre sus orígenes y parientes biológicos, una vez alcanzada la mayoría de edad».

A mayor abundamiento, convienen precisar que, en los supuestos de acogimiento familiar, tendrán los siguientes derechos:

«a) Participar plenamente en la vida familiar del acogedor.

b) Mantener relación con la familia de acogida tras el cese del acogimiento si la Entidad Pública entiende que conviniere a su interés superior y siempre que lo consintieren el menor si tuviere suficiente madurez y, en todo caso, si fuera mayor de doce años, la familia de acogida y la de origen o, en su caso, la familia adoptiva o de acogimiento permanente.

c) Solicitar información o pedir, por sí mismo si tuviera suficiente madurez, el cese del acogimiento familiar».

Por último, convienen puntualizar que, de forma conjunta con los derechos antes mencionados, el precepto también reconoce a los menores que se encuentren en supuestos de acogimiento residencial, un amplio abanico de derechos de carácter específico [art. 21 bis. 3 LOPJM], que han sido en su gran mayoría reconocidos por la legislación autonómica, en pro de la protección del menor $y$, que a la par, se acogen a las recomendaciones realizadas por el CONSEJO GENERAL DEL PODER JUDICIAL en el Informe al Anteproyecto de la Ley de la Protección a la Infancia ${ }^{83}$. Estos derechos se concretan en los siguientes:

«a) Respeto a la privacidad y a conservar sus pertenencias personales siempre que no sean inadecuadas para el contexto educativo.

${ }^{83}$ Op. $\quad$ cit., $\quad$ pp. 51-52. Disponible en: http://www.congreso.es/docu/docum/ddocum/dosieres/sleg/legislatura_10/spl 78/pdfs/15.pdf. [Consultado el 22 de noviembre de 2018]. 
b) Participar en la elaboración de la programación de actividades del centro y en el desarrollo de las mismas.

c) Ser escuchado en caso de queja y ser informado de todos los sistemas de atención y reclamación que tienen a su alcance, incluido el derecho de audiencia en la Entidad Pública».

\section{LA REMOCIÓN DE LA GUARDA Y EL CESE DEL ACOGIMIENTO}

En primer término y, por lo que respecta a este nuevo régimen jurídico introducido por Ley 26/2015, de 28 de julio, convine puntualizar que se cierra con las novedosas previsiones realizadas en sede de cese del acogimiento. Previsiones que, en la actualidad, plantean problemas de carácter interpretativo.

En este sentido, y como primera cuestión, conviene aludir la distinción terminológica realizada entre remoción de guarda y el cese del acogimiento, realizada por el artículo 173 CC.

Así, el precepto establece que: «Si surgieren problemas graves de convivencia entre el menor y la persona o personas a quien hubiere sido confiado la guarda en acogimiento familiar, aquél, el acogedor, el Ministerio Fiscal, los progenitores o tutor que no estuvieran privados de la patria potestad o de la tutela o cualquier persona interesada podrán solicitar a la Entidad Pública la remoción de la guarda»[art. 173. 3 CC]. Contemplándose con ello la posibilidad de la remoción de la guarda para el caso de problemas graves de convivencia entre el menor y los acogedores.

Por su parte, también el artículo prevé las causas en las que procederá el cese del acogimiento, en sus variantes tradicionales, es decir, la administrativa y la judicial, ampliándose o incorporándose, en la actualidad, algunas causas de carácter adicional que actúan de forma automática, como sería el caso de la muerte o declaración de fallecimiento del acogedor o acogedores del menor o, por la mayoría de edad de éste [art. 173. 4 CC], suprimiéndose la referencia a la cesación del acogimiento por la decisión de las personas que lo tuviesen acogido, previa comunicación de éstas a la Entidad Pública y, omitiéndose la referida al fallecimiento del menor ${ }^{84}$, a la que sí se alude en algunas legislaciones forales ${ }^{85}$,

\footnotetext{
${ }^{84}$ MAYOR DEL HOYO, M. ․ V., precisa que «es una lástima que se aluda al fallecimiento del acogedor y no al del menor», quedándole "la duda de que si en la redacción de la letra c) del precepto se ha omitido involuntariamente la conjunción " $Y$ " entre "del acogedor o acogedores y "del menor"» ("El nuevo acogimiento: régimen jurídico tras la Ley 26/2015, de 28 de julio». En El nuevo régimen jurídico o del menor. La reforma legislativa de 2015, (directora María Victoria Mayor del Hoyo), Ed. Thomson Reuters Aranzadi, Navarra, 2017, p. 233).

${ }^{85}$ Así, el artículo 55. 1 de la Ley 1/2006, de 28 de febrero, de Protección de Menores de La Rioja, establece que: "La situación de desamparo y la consiguiente tutela de la Administración de la Comunidad Autónoma de La Rioja cesarán por las siguientes causas: a) Mayoría, habilitación de edad o matrimonio del menor. b) Adopción del menor. c) Resolución judicial firme. d) Resolución del titular de la Consejería competente, a propuesta de la
} 
aunque como algunos autores ${ }^{86}$ precisan acertadamente se sobreentiende que el acogimiento también cesa si se da dicha circunstancia.

De lo anterior, conviene precisar que la doctrina ha puesto de manifiesto su disconformidad en la distinción incluida por el legislador, entre remoción de guarda y cese del acogimiento, debido a que dicha diferenciación resulta a todas luces innecesaria, debido a que en todo caso lo que origina es confusión y, en consecuencia como LÓPEZ AZCONA precisa "se está extrapolando al acogimiento familiar una figura como es la remoción propia de la tutela ordinaria, prescindiendo de las garantías de que se rodea ésta en los arts. 248 a 250 CC en sede de tutela ordinaria, en relación con el art. 49 LJV» ${ }^{87}$.

En este punto, téngase presente que la remoción de la tutela necesita de declaración judicial, que deberá ser previa a la tramitación del expediente de jurisdicción voluntaria y, en el que será oído el tutor y el menor que se encuentre sujeto a tutela y sea mayor de doce años o, aunque menor de tal edad, cuente con suficiente madurez, así como el Ministerio Fiscal.

Asimismo, y para el caso de oposición, el expediente se realizará por vía contenciosa, debiendo ser citados los interesados a una vista $y$, continuándose la tramitación del expediente a través de lo establecido para el juicio verbal. No obstante, durante la tramitación del expediente de remoción de la guarda, el Juez podrá suspender en sus funciones al tutor y nombrar un defensor judicial al tutelado $y$, para el supuesto de declararse judicial la remoción, entonces se procederá al nombramiento de un nuevo tutor [arts. 248 a 250 CC y 29 LV].

En suma, con la nueva redacción del precepto la remoción es atribuida a la Entidad Pública, excluyéndose de raíz toda intervención judicial y, encontrándose carente, tanto de

Comisión de adopción, acogimiento y tutela, cuando hubieren desaparecido los hechos o circunstancias que motivaron la situación de desamparo y resultare conveniente para el menor la reintegración en su familia. e) Constitución de la tutela ordinaria sobre el menor, en los casos a que se refiere el artículo 61 de esta Ley. f) Fallecimiento del menor"; el artículo 124 de la Ley 14/2010, de 27 de mayo, de los derechos y las oportunidades en la infancia y la adolescencia, de Cataluña, precisa que: "Las medidas de protección se extinguen por: a) Adopción. b) Alcance de la mayoría de edad, emancipación o habilitación de edad. c) Resolución judicial civil firme. d) Constitución de la tutela. e) Acuerdo del órgano competente que declara que han desaparecido las circunstancias que habían dado lugar a la adopción de la medida. f) Muerte o declaración de defunción del niño o del adolescente»; el artículo 72 de la Ley 3/2005, de 18 de febrero, de Atención y Protección a la Infancia y la Adolescencia, del País Vasco, establece que: «El acogimiento familiar del niño, niña o adolescente podrá cesar por las siguientes causas: a) Por resolución judicial firme. b) Por decisión de las personas que lo ejercen, previa comunicación de éstas a la administración pública competente. c) A petición del tutor o de los padres y madres que tengan la patria potestad y reclamen su compañía. d) Por resolución administrativa de la entidad pública, tenga o no la tutela, cuando lo considere necesario para salvaguardar el interés del niño, niña o adolescente, oídas las personas acogedoras. e) A petición de la persona menor de edad, siempre que tenga los doce años cumplidos. f) Por fallecimiento del niño, niña o adolescente o de la persona acogedoran.

${ }^{86}$ Vid., en este sentido, BERROCAL LANZAROT, A. I. «La guarda y tutela administrativa..., op. cit., p. 215.

${ }^{87}$ Op. cit., p. 38. 
procedimiento ad hoc como de previsión de medida de protección alternativa alguna para el supuesto de que sea declarada y, por tanto, únicamente se puede adoptar por la Entidad Pública a instancia de parte.

A mayor abundamiento, conviene precisar que en sede de legitimación el orden de prelación para solicitar la remoción de la guarda será el siguiente: el propio acogido, sin exigencia de la edad de doce años o, de la suficiente madurez; los acogedores; el Ministerio Fiscal; los progenitores no privados de la patria potestad o, el tutor ordinario no removido de la tutela y, en general, cualquier otro interesado -expresión en la que podría tener cabida la familia extensa del menor ${ }^{88}$.

Asimismo, el precepto prevé que la remoción de la guarda únicamente será posible para el caso de que se susciten graves problemas de convivencia entre el menor acogido y los acogedores, prescindiéndose del resto de causas de remoción de tutela ordinaria contempladas en el texto legal [art. 247 CC], es decir, los que incurran en causa legal de inhabilidad; los que se conduzcan mal en el desempeño de la tutela, ya sea por incumplimiento de los deberes propios del cargo o, por la notoria ineptitud de su ejercicio y, los que tengan graves y continuados problemas de convivencia.

Por su parte, también la denominación utilizada por la reforma practicada por Ley $26 / 2015$, de 28 de julio y, concretada, en remoción de la guarda -que no del acogimientoresulta confusa y carente de sentido al poder ser interpretada en el sentido de que continua el acogimiento, pero privado de contenido, debido lógicamente a que el acogedor ha sido removido de la guarda.

En relación al cese del acogimiento, conviene puntualizar que el nuevo texto contenido en el apartado cuarto del mencionado precepto, tras la supresión del acogimiento judicial no tiene sentido alguno que siga manteniendo la distinción entre el cese judicial y el cese administrativo, máxime cuando en la redacción anterior el cese judicial quedaba circunscrito al acogimiento dispuesto por el Juez y, en consecuencia, lógico habría sido por el legislador establecer en qué supuestos procede el cese judicial, en el entendido de que en su propia Disposición Transitoria Segunda, dispone que: «los acogimientos constituidos judicialmente con anterioridad a la entrada en vigor de la ley podrán cesar por resolución de la Entidad Pública sin necesidad de resolución judicial».

Por otra parte, el cese administrativo queda circunscrito para el caso de que la Entidad Pública que ostente la tutela o guarda del menor acogido «lo considere necesario para salvaguardar el interés del mismo», con la discrecionalidad que lo anterior implica, debido a que la propia naturaleza del interés del menor, lo considera como un concepto jurídico de carácter indeterminado.

\footnotetext{
${ }^{88}$ LÓPEZ AZCONA, op. cit., p. 39.
} 
Punto en el que LÓPEZ AZCONA, precisa que "ha de valorarse muy positivamente el hecho de que el art. 2 LOPJM en su redacción dada por la LO 8/2015 haya dotado de este concepto de una mayor concreción, en línea con la Observación núm. 14 (2013) del Comité de los Derechos del Niño de Naciones Unidas» ${ }^{89}$. Y, añade que "el nuevo art. 2 LOPJM dota de contenido a este concepto en una triple dimensión: Por un lado, como un derecho sustantivo del menor a que su mejor interés sean valorado y considerado como primordial en todas las acciones y decisiones que le conciernan, tanto en el ámbito público como privado. De otra parte, como criterio interpretativo, de forma que, si una norma jurídica puede interpretarse de diversas maneras, se debe optar por la interpretación que mejor responda a los intereses del menor. $Y$, por último, como norma de procedimiento a tener en cuenta a la hora de adoptar cualquier medida administrativa o judicial cuyo destinatario sea un menor, lo que se traduce en las siguientes garantías a observar en el correspondiente procedimiento: a) derecho a ser informado, oído y escuchado; b) intervención en el proceso de profesionales cualificados; c) participación en el proceso de sus representantes legales o del defensor judicial en caso de conflicto de intereses y del Ministerio fiscal; d) adopción de resoluciones motivadas; $y$ e) recursos que permitan revisar aquellas decisiones que no hayan considerado como prioritario el interés del menor.

A partir de ahí, el precepto precitado fija novedosamente, en línea con la Observación general núm. 14 (2013) del Comité de los Derechos del Niño de Naciones Unidas sobre el derecho del niño a que su interés superior sea una consideración primordial, una serie de criterios generales y elementos comunes de ponderación a tener en cuenta para determinar en cada caso concreto el interés del menor y que, en todo caso, deben precisarse en la motivación de la decisión adoptada (en nuestro caso, del acuerdo de mediación), a fin de conocer si ha sido correcta (o no) la aplicación del principio del interés superior del menor. De no ser así, la decisión será susceptible del correspondiente recurso. En particular, los criterios comunes (o más exactamente, los derechos de los menores) para tener en cuenta son: a) la protección a la vida y desarrollo del menor y la satisfacción de sus necesidades básicas; $b$ ) los deseos y opiniones del menor, en función de su grado de madurez; c) la vida del menor en un entorno familiar adecuado y libre de violencia; y d) la preservación de la identidad, cultura, y religión del menor. Por otra parte, se contemplan como elementos generales de ponderación: a) la edad y madurez del menor; b) su especial vulnerabilidad; c) el irreversible efecto del transcurso del tiempo en su desarrollo; $y$ d) la estabilidad en las soluciones adoptadas.

Por añadidura, se fijan unos criterios de resolución de conflictos para el caso de colisión del interés superior del menor con cualquier otro interés legítimo. Así, como criterio prioritario, se otorga prevalencia a las medidas que, respondiendo al interés del menor, respeten los otros intereses en juego; y subsidiariamente, en caso de no ser posible conjugar todos los intereses en juego, se atribuye prioridad el interés superior del menor ${ }^{90}$.

\footnotetext{
${ }^{89}$ Op. cit., p. 40.

${ }^{90}$ LÓPEZ AZCONA,op. cit., Nt. 109, pp. 40 y 41.
} 
Si bien, esta decisión podrá ser adoptada ya de oficio o, ya a instancia de parte por la Administración en idénticos términos a los previstos por la regulación anterior.

A mayor abundamiento, conviene precisar que en sede de legitimación el orden de prelación para solicitar el cese a instancia de parte es el siguiente: los progenitores y tutor ordinario sin especificación de que no han de estar privados de la patria potestad o, removido de la tutela; los acogedores -desde el instante en que han sido privados de renunciar al acogimiento- y el propio menor acogido con suficiente madurez, por tanto, a partir de los doce años [art. 173. 4 letra b) CC].

Por otra parte, se introduce un trámite de audiencia que será previa a la resolución administrativa de cese $y$, en la que serán oídos, tanto los acogedores y el menor ${ }^{91}$, de conformidad con lo establecido en el artículo 9. 2 LOPJM, como los progenitores o el tutor ordinario, carente esto último de sentido alguno, debido a que éstos no tienen derecho alguno de audiencia en la constitución del acogimiento familiar.

Por último, el precepto, aunque incorpora siguiendo las recomendaciones realizadas en su día por el CONSEJO GENERAL DEL PODER JUDICIAL, dos causas de cese automático, concretadas, de una parte, en la muerte o declaración de fallecimiento del acogedor o acogedores y, de otra, en la mayoría de edad del menor acogido [art. 173. 4 letras c) y d) CC], de forma parecida a lo establecido, tanto en la patria potestad [art. $169 \mathrm{CC}$ ], como en la tutela ordinaria [art. $176 \mathrm{CC}$ ] ${ }^{92}$, lo cierto es que omite el transcurso del plazo de duración establecido para el acogimiento temporal o de urgencia.

Causa que, sí se encuentra regulada por la gran mayoría de las legislaciones autonómicas, como sería el caso, por ejemplo, del artículo 52. 1 letra a) del Decreto 93/2001, de 22 de mayo, del Gobierno Valenciano, por el que se aprueba el Reglamento de Medidas de Protección Jurídica del Menor en la Comunidad Valenciana, al prever que: «El cese del acogimiento familiar del menor se producirá: [...] Por transcurso del tiempo de duración previsto en la resolución de adopción de la medida y, en su caso, de la prórroga»o, del art. 95. 1 letra c) del Decreto 190/2008, de 7 de octubre, del Gobierno de Aragón, por el que se aprueba el Reglamento de medidas de protección de menores en situación de riesgo o desamparo, al establecer que: «El cese del acogimiento familiar del menor se producirá: [...] Por el cumplimiento del plazo fijado».

Además, conviene precisar que, aunque con la nueva reforma se prescinde de la renuncia al acogimiento por los acogedores -contemplada en el régimen anterior-, lo cierto es que les reconoce legitimación para poder solicitar su cese y, por tanto, a este cargo de acogedor se le atribuye carácter obligatorio, impidiéndose con ello que el acogimiento

\footnotetext{
${ }^{91}$ Vid., ALVÁREZ OLALLA, P. «Modificaciones de Derecho Civil contenidas en el Anteproyecto de Ley de Protección de la Infancia», Aranzadi civil mercantil, vol. 2, número 4, 2014, p. 46.

${ }^{92}$ Vid., CONSEJO GENERAL DEL PODER JUDICIAL (PLENO). op. cit., p. 76. Disponible en: http://www.congreso.es/docu/docum/ddocum/dosieres/sleg/legislatura 10/spl 78/pdfs/15.pdf. [Consultado el 22 de noviembre de 2018].
} 
quede al libre albedrío de quien lo ejerza, con el consiguiente perjuicio que se le puede originar al menor acogido. Asimismo, la decisión sobre esta solicitud de cese corresponde resolverla a la Administración, quien actuará en pro del interés del menor. Punto en el que, LÓPEZ AZCONA, entiende con acierto que "parece razonable que, si los acogedores muestran su falta de predisposición y voluntad a continuar con el acogimiento, la Administración proceda a su cese para salvaguardar así el interés del menor acogido" ${ }^{93}$.

Para cerrar las presentes líneas, conviene aludir a la inexistencia de regulación alguna en relación con la modificación del acogimiento familiar, para el supuesto de alteración de las circunstancias.

Cuestión que sí se encuentra regulada en la legislación autonómica ${ }^{94} y$, que por omisión u olvido debería haber sido regulada de forma expresa por el legislador estatal, debido a la enorme importancia que esta cuestión tiene en la práctica habitual de nuestros tribunales.

\section{CONCLUSIONES}

La institución del acogimiento familiar se configura como una medida de protección del menor que se encuentra inmerso en una situación familiar de carácter conflictivo. De modo que, se trata de una medida protectora de carácter personal, debido a que los acogedores realizan de forma provisional todas las obligaciones derivadas del cuidado del menor, pero sin asumir ni la administración de los bienes, ni las funciones de representación.

Asimismo, esta institución, debe ser concebida como una medida de carácter alternativo de protección o, recurso de apoyo temporal para aquellos supuestos que derivados de una situación de crisis familiar transitoria se hace incompatible la permanencia del menor con su familia de origen. De ahí, su enfoque como una medida que proporcione al menor un ambiente adecuado o, un entorno familiar alternativo permitiéndole desarrollarse y mantener el contacto con su familia de origen, siempre que no le resulte perjudicial e, indudablemente, cesando cuando sea innecesaria.

En la actualidad y, con la aprobación de la nueva normativa en materia de protección a la infancia y a la adolescencia, en nuestro país, se han agilizado los procesos de acogimiento; se ha mejorado la atención a la infancia en riesgo y a menores víctimas de

\footnotetext{
${ }^{93}$ Op. cit., p. 42.

${ }^{94}$ Así: el artículo 94 del Decreto 190/2008, de 7 de octubre, del Gobierno de Aragón, por el que se aprueba el Reglamento de medidas de protección de menores en situación de riesgo o desamparo, establece que: En caso de variación de las circunstancias que dieron lugar a la constitución del acogimiento familiar, el Consejo Aragonés de la Adopción, a propuesta de la Dirección Provincial correspondiente, y previa audiencia del menor y de los interesados, promoverá la modificación en la modalidad de acogimiento» y, el artículo 72 de la Ley Foral 15/2005, de 5 de diciembre, de promoción, atención y protección a la infancia y a la adolescencia de Navarra, precisa que: «Podrá modificarse, o solicitar la modificación correspondiente al juzgado competente en el supuesto de acogimientos constituidos judicialmente, la modalidad del acogimiento cuando se considere beneficioso para el menor conforme al procedimiento reglamentariamente establecida».
} 
violencia $y$, se ha garantizado la especial protección de los menores en todo el Estado respondiendo a sus concretas necesidades.

Además, con esta reforma se ha reforzado el régimen jurídico de la guarda de hecho, agilizándose con ello una medida en pro de la protección de menores de edad y personas con discapacidad ante aquellas situaciones derivadas, ya del indebido cumplimiento de sus funciones por parte de sus propios progenitores o tutores, ya por la inexistencia de estas personas. Por tanto, aunque se han introducido ciertas previsiones, al objeto de otorgar una estabilidad y una seguridad jurídica a los guardadores de hecho, lo cierto es que se ha perdido la oportunidad de realizar una reforma más completa de la institución de la guarda.

Asimismo, del hecho de no haberse realizado una reforma integral del sistema de protección de los menores y de las personas con discapacidad, se denota la carencia de respuesta a una gran parte de los requerimientos del sistema de apoyos de la Convención de Naciones Unidas de las personas con discapacidad, comportándose un amplio abanico de contradicciones, cuando lo que debería haberse realizado es una reforma más completa y sistemática, con la finalidad de adaptar nuestro ordenamiento jurídico a las disposiciones contenidas en la Convención de Naciones Unidas de las personas con discapacidad.

Para finalizar, conviene concluir que la reforma legislativa debería haber contemplado dentro del régimen jurídico de la guarda de hecho un deber de comunicación a la autoridad judicial, al Ministerio Fiscal o, a la Entidad Pública competente en el respectivo territorio para la protección de los menores de edad o de las personas con discapacidad, amén de delimitar el supuesto de hecho de la guarda y de las facultades del guardador, con la pretensión de establecer a qué ámbito quedan circunscritos, resultando además, cuando menos cuestionable el hecho de que se haya advertido la posibilidad de que el guardador asuma únicamente funciones tutelares. No obstante, conviene precisar que recientemente, se ha aprobado por el Pleno del Consejo General del Poder Judicial un informe que avala el Anteproyecto de Ley elaborado por el Ministerio de Justicia para reformar la legislación civil y procesal en materia de discapacidad. Anteproyecto en el que se establece la institución de la curatela como medida de protección de las personas con discapacidad, procurándose con ello realizar una interpretación y aplicación de nuestro ordenamiento jurídico acorde con los principios recogidos en la Convención de Naciones Unidas de las personas con discapacidad, así como con el sistema de apoyos.

\section{REFERENCIAS BIBLIOGRÁFICAS}

ABAD ARENAS, E. "Acogimiento de Menores. Teoría y Práctica», (Coordinadora Inmaculada García Presas), 1. ed., Ed., Juruá Editorial, Porto, Portugal, 2018.

ÁLVAREZ OLALLA, P. «Modificaciones de Derecho Civil contenidas en el Anteproyecto de Ley de Protección de la Infancia», Aranzadi civil mercantil, vol. 2, número 4, 2014, pp. 37-49.

AMORÓS, P y PALACIOS, J. «Acogimiento familiar», Alianza-Ensayo, Madrid, 2004. 
BERROCAL LANZAROT, A. I. La "revitalización» de la guarda de hecho tras la Ley 26/2015, de 28 de julio de modificación del sistema de protección a la infancia y a la adolescencia (I)», Revista Crítica de Derecho Inmobiliario, número 757, 2016, pp. 2845-2868.

BERROCAL LANZAROT, A. I. "La guarda y tutela administrativa de menores. El acogimiento familiar y residencial». En La protección jurídica de la infancia y la adolescencia tras la Ley Orgánica 8/2015, de 22 de julio y la Ley 26/2015, de 28 de julio, (Coordinadores Ana Isabel Berrocal Lanzarot y Carmen Callejo Rodríguez), Wolters Kluwer España. La Ley, 2017, pp. 131-259.

CAPARROS CIVERA, N y JIMÉNEZ-AYBAR, I. «EI acogimiento familiar: aspectos jurídicos y sociales», Ed. Rial, Madrid, 2001.

CONSEJO GENERAL DEL PODER JUDICIAL (PLENO). "Informe al Anteproyecto de Ley de protección a la infancia», 2014, pp. 1-113. Disponible en: http://www.congreso.es/docu/docum/ddocum/dosieres/sleg/legislatura 10/spl 78/pdfs/15 .pdf. [Consultado el 22 de noviembre de 2018].

DEFENSOR DEL PUEBLO DE ESPAÑA. «Centros de protección de menores con trastorno de conducta y en situación de dificultad social. Informes, estudios y documentos», Ed. Defensor del Pueblo, Madrid, 2009.

DIEZ GARCÍA, H. «El acogimiento familiar simple como una de las formas de ejercer la guarda de menores», Ed. Ministerio de Trabajo y Asuntos Sociales, Madrid, 2004.

EGEA FERNÁNDEZ, J. «Comentarios a los artículos 173-174 CC; Artículos 63.16; 1825-1828 LEC y Disposición Adicional 2.a». En Comentarios a las reformas del Código civil. Desde la Ley 21/1987, de 11 de noviembre, a la Ley 30/1991, de 20 de diciembre, (Coordinador Rodrigo Bercovitz Rodríguez-Cano), Ed. Tecnos, Madrid, 1993.

FLUITERS CASADO, R. «Acogimiento y adopción», Cuadernos de Derecho Judicial, número 16, 1996, pp. 279-336.

GARCÍA GARNICA, M. a C. "La guarda como medida de protección de menores y personas con discapacidad tras su reforma por la Ley 26/2015, de 28 de julio, de modificación del sistema de protección a la infancia y a la adolescencia», Anuario de derecho civil, vol. 70, número 4, 2017, pp. 1375-1421.

GARCÍA GARNICA, M. a C. «Discapacidad y dependencia (II): Configuración y contenido de su situación jurídica». En Tratado de derecho de la persona física, (coordinadora M. Carmen Gete-Alonso Calera y Judith Solé Resina), vol. 2, 2013, pp. 211-274.

LECIÑERA IBARRA, A. "La nueva dimensión de la guarda de hecho de las personas con discapacidad tras la reforma del art. 303 CC por la Ley 26/2015, de 28 de julio, de modificación del sistema de protección a la infancia y a la adolescencia», Revista de derecho de familia: Doctrina, Jurisprudencia, Legislación, número 73, 2016, pp. 91-110. 
LINACERO DE LA FUENTE, M.‥ «Protección jurídica del menor», Ed. Montecorvo, Madrid, 2001.

LÓPEZ AZCONA, A. «Luces y sombras del nuevo marco jurídico en materia de acogimiento y adopción de menores: a propósito de la Ley Orgánica 8/2015 y la Ley 26/2015 de modificación del sistema de protección a la infancia y adolescencia», Boletín de información del Ministerio de Justicia, año LXX, número 2185, enero, 2016, pp. 3-89.

LÓPEZ SÁNCHEZ, F. et al. "Actuaciones frente a los malos tratos y el desamparo de menores», Centro de Publicaciones del Ministerio de Asuntos Sociales, Madrid, 1995.

LÓPEZ SAN LUIS, R. "La regulación del acogimiento tras las últimas reformas legislativas en materia de protección a la infancia y a la adolescencia en el derecho español», Revista Chilena de Derecho y Ciencia Política, vol. 7, número 2, 2016, pp. 47-100

MAYOR DEL HOYO, M.a V. "El nuevo acogimiento: régimen jurídico tras la Ley $26 / 2015$, de 28 de julio». En El nuevo régimen jurídico o del menor. La reforma legislativa de 2015, (directora María Victoria Mayor del Hoyo), Ed. Thomson Reuters Aranzadi, Navarra, 2017, pp. 219-248.

MAYOR DEL HOYO, M.a V. "Comentario a los artículos 173, 173 bis y 174 del Código Civil». En Código Civil comentado, vol. I, (directores Ana Cañizares Laso, Pedro de Pablo Contreras, Javier Ortuña Moreno y Rosario Valpuesta Fernández), 2. a ed., Ed. Civitas, Thomson Reuters, Cizur Menor, Navarra, 2016, pp. 888-915.

MAYOR DEL HOYO, M.a. V. "Sistema tuitivo del menor en el Código civil español: acogimiento y otras medidas de protección». En El acogimiento y otras medidas de protección de la infancia y adolescencia desamparada, Ed. Universitat de Lleida, 2012, pp. 51-68.

MORENO FLÓREZ, R. M. «Acogimiento Familiar», 1. a ed., Ed. Dikynson, Madrid, 2012.

MORETÓN SANZ, M.a F. "El guardador de hecho ante la dependencia. Revisión de los procedimientos autonómicos y de las declaraciones «bajo su responsabilidad", Diario La Ley, número 7246, 2009, pp. 1-16.

PALMA DEL TESO, A. "Administraciones públicas y protección de la infancia, en especial, estudio de la tutela administrativa de los menores desamparados», Ed. Instituto Nacional de Administración Pública (INAP), Madrid, 2006.

PARRA LUCAN, M.a A. "La guarda de hecho de las personas con discapacidad». En Los mecanismos de guarda legal de las personas con discapacidad tras la Convención de Naciones Unidas, (coordinadora Sofía de Salas Murillo), 2013, pp. 211-264.

PARRA LUCAN, M.a A. "Comentario al artículo 303». En Comentarios al Código Civil, T. II, (director Rodrigo Bercovitz Rodríguez-Cano), Ed. Tirant Lo Blanch, 2013, pp. 2530-2543. 
POYATOS GARCÍA, A. "Historia y evolución del acogimiento familiar de menores y el contexto de la Comunidad Valenciana», TS nova: trabajo social y servicios sociales, número 5, 2012, pp. 23-36.

ROSSER LIMIÑANA, A. "Marco legislativo del acogimiento familiar», Alternativas. Cuadernos de Trabajo Social, número 6, 1998, pp. 259-267.

SAINZ-CANTERO CAPARRÓS, B. "El modelo común para la intervención con menores en riesgo y desamparo propuesto por el Anteproyecto de Ley de Protección de la infancia", Revista de Derecho Civil, vol. I, número 4 (octubre-diciembre), 2014, pp. 107-153.

SÁINZ-CANTERO CAPARRÓS, M. a B y PARDO MARTÍNEZ, E. "Régimen jurídico de los centros de protección y reforma de menores», Ed. Comares, Granada, 2010.

SANIDAD, SERVICIOS SOCIALES E IGUALDAD. "Anteproyecto de ley de modificación del Sistema de Protección a la Infancia y a la Adolescencia». Consejo de Estado: Dictámenes. Referencia: 1093/2014, Fecha de aprobación: 27/11/2014. Disponible en: https://www.boe.es/buscar/doc.php?id=CE-D-2014-1093\&lang=en [Consultado el 21 de noviembre de 2018].

SENADO. "Informe especial de la Comisión Especial de Estudio de la problemática de la adopción nacional y otros temas afines», Boletín Oficial de las Cortes Generales, IX Legislatura, Serie I: Boletín General, número 545, de 17 noviembre 2010, pp. 1-54.

TOSCANO GIL, F. «El acogimiento administrativo de menores: Análisis de su problemática en sede judicial», Actualidad Jurídica Aranzadi, número 708, 2006, pp. 8-10. 